\title{
Sol-Gel Waveguide-Based Sensor for Structural Health Monitoring on Large Surfaces in Aerospace Domain
}

\author{
Maxime Royon ${ }^{1, *}$, Damien Jamon ${ }^{1}{ }^{\mathbb{D}}$, Thomas Blanchet ${ }^{1}$, François Royer ${ }^{1} \mathbb{D}$, Francis Vocanson ${ }^{1}$,

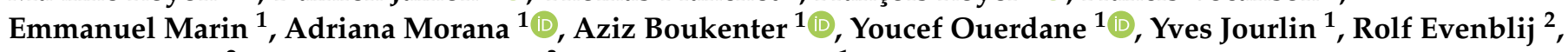 \\ Thijs Van Leest ${ }^{2}$, Marie-Anne de Smet ${ }^{3}$ and Sylvain Girard ${ }^{1}$
}

1 Laboratoire H. Curien, UJM-CNRS-IOGS, Université de Saint-Etienne, 18 Rue Du Pr. Benoît Lauras, 42000 Saint-Etienne, France; damien.jamon@univ-st-etienne.fr (D.J.); thomas.blanchet@univ-st-etienne.fr (T.B.); francois.royer@univ-st-etienne.fr (F.R.); francis.vocanson@univ-st-etienne.fr (F.V.); emmanuel.marin@univ-st-etienne.fr (E.M.); adriana.morana@univ-st-etienne.fr (A.M.); aziz.boukenter@univ-st-etienne.fr (A.B.); ouerdane@univ-st-etienne.fr (Y.O.); yves.jourlin@univ-st-etienne.fr (Y.J.); sylvain.girard@univ-st-etienne.fr (S.G.)

2 Photonfirst, Pyrietstraat 2, 1812 SC Alkmaar, The Netherlands; rolf.evenblij@photonfirst.com (R.E.); thijs.vanleest@photonfirst.com (T.V.L.)

3 Airbus, 316 Route De Bayonne, 31060 Toulouse, France; marie-anne.de-smet@airbus.com

* Correspondence: maxime.royon@univ-st-etienne.fr

check for updates

Citation: Royon, M.; Jamon, D.; Blanchet, T.; Royer, F.; Vocanson, F.; Marin, E.; Morana, A.; Boukenter, A.; Ouerdane, Y.; Jourlin, Y.; et al. Sol-Gel Waveguide-Based Sensor for Structural Health Monitoring on Large Surfaces in Aerospace Domain. Aerospace 2021, 8, 109. https:// doi.org/10.3390/aerospace8040109

Academic Editor: Zhongqing Su

Received: 22 March 2021

Accepted: 12 April 2021

Published: 14 April 2021

Publisher's Note: MDPI stays neutral with regard to jurisdictional claims in published maps and institutional affiliations.

Copyright: (C) 2021 by the authors. Licensee MDPI, Basel, Switzerland. This article is an open access article distributed under the terms and conditions of the Creative Commons Attribution (CC BY) license (https:/ / creativecommons.org/licenses/by/ $4.0 /)$.

\begin{abstract}
The potential of sol-gel-based optical sensors is investigated for applications in the aerospace domain. To this aim, a low-cost and non-intrusive sol-gel sensor based on waveguides, arranged as a 2D matrix structure, is fabricated by UV photolithography for delamination and damage detection. Two different organic-inorganic sol-gels were selected to fabricate the photonic device: $\mathrm{TiO}_{2}-\mathrm{SiO}_{2}$ and $\mathrm{ZrO}_{2}-\mathrm{SiO}_{2}$, acting as the waveguide core and the cladding, respectively. A systematic study was performed to determine the manufacturing parameters controlling their properties. The results show that large surfaces can be functionalized via sol-gel methods using the direct laser-writing approach. The structures are characterized in terms of refractive index, and the guiding properties were investigated through simulations and experiments, indicating an excellent behavior regarding the light guidance in a straight waveguide or in the 2D matrix structure grid. Additionally, preliminary tests show that the presence of impact can be easily detected after damage through the induced optical losses on large surfaces. This proof of concept sensor is a promising tool for structural health monitoring. To achieve the ultimate goal, the integration of this photonic sensor will be later performed on aircraft wings.
\end{abstract}

Keywords: sol-gel sensors; photolithography; direct writing technique; UV photopolymerization; damage sensing; structural health monitoring; aircraft wings

\section{Introduction}

Structural health monitoring (SHM) plays a very important role in assessing architectures operating in the aerospace domain. SHM technologies for damage detection have been developed based on several principles, such as piezoelectric materials [1], ultrasonic waves [2] or even passive acoustic sensors [3]. However, some of these SHM devices can be relatively expensive and hard to deploy on large surfaces [4]. In the last decades, optical fiber sensors (OFSs) have also been deployed, acting as a real-time in situ monitoring device, and the influence of the defects caused by impacts was largely investigated. More specifically, OFSs for SHM application can be divided into three categories: interferometric for a single point detection scheme [4,5]; Bragg grating-based [6] and Rayleigh or Brillouin scattering-based sensors [7] acting for quasi-distributed and distributed measurements, respectively. Even if these techniques reveal important performance, namely in terms of strain monitoring and impact damage detection, their use for a precise impact detection 
needs further developments, such as a network of optical fibers notably to improve the spatial resolution on the defect location.

Interestingly, in parallel to OFSs, the literature shows that the sol-gel materials can also be of interest regarding the aerospace domain. For example, it can concern creating protective layers against corrosion [8] or developing magnetic hybrid sol-gel materials [9]. However, the detection of defects using piezoceramic sensors fabricated by a sol-gel spray technique for SHM [10] has already been reported. From a chemical point of view, the sol-gel process, based on hydrolysis and condensation reactions, leads to the synthesis of glass-like materials [11]. Metal alkoxides precursors (from $\mathrm{Ti}, \mathrm{Zr}, \mathrm{Si} . .$. ) are used to create an inorganic metal oxides matrix $\left(\mathrm{TiO}_{2}, \mathrm{ZrO}_{2}, \mathrm{SiO}_{2} \ldots\right)$, and the resulting materials can be tailored in terms of mechanical and optical properties by adjusting the chemical conditions and the molar ratio. The use of precursors containing an organic chain can confer a UV photosensitivity to the final mixture, a crucial step regarding the manufacturing of sol-gel devices. Additionally, a photoinitiator can also be incorporated to increase the photosensitivity $[12,13]$. The mechanisms governing the interaction of incident light with photoresists lead to two different classes of sensitive materials. The first class corresponds to negative photoresists (such as sol-gel), where the zone exposed to UV photons is polymerized, inducing a densified pattern. During the development process in an alcoholic solution, the area exposed to light is not removed, while the unexposed one is dissolved, thus revealing the photonic device. The second class corresponds to positive photoresists where the UV exposed part is removed during the development procedure. By photolithographic processes, it is thus possible to microstructure different films. This great flexibility allows the fabrication of sol-gel devices at low cost, covering a wide area of applications, such as $\mathrm{pH}$ and gas sensors [14], water decontamination [15] and creating photonic sensors [16,17]. Knowing the potentiality of this approach, we tried to find if the sol-gel process can enable the fabrication of photonic devices based on the light propagation for SHM application.

In the framework of the Cleansky2 (Horizon 2020) project advanced damage detection through optical sensor network (ADD-ON), we demonstrate the feasibility of using a non-intrusive sol-gel approach for damage sensing over large surfaces. More specifically, a low-cost sensor for delamination and damage detection based on the light transport of sol-gel waveguides is presented. This photonic device should be integrated on aircraft parts, such as wings, considering the specific environmental constraints of the aerospace domain for SHM usage. Figure 1 illustrates the targeted final architecture of the sensor to be manufactured. This latter is based on waveguides arranged as a $2 \mathrm{D}$ sol-gel grid able to be deployed on a large surface $(40 \mathrm{~cm} \times 40 \mathrm{~cm})$. After light injection into all the waveguides, the detection and impact localization can be clearly observed through the 2D mapping grid, where the optical mode extinction or intensity decrease indicates the presence of damages. Moreover, the spatial resolution of the sol-gel sensor is totally determined by the distance between two adjacent waveguides. In this manuscript, we present the different negative sol-gels layers acting as the waveguide core and cladding, respectively. The aerospace domain already has experience with sol-gel deposition for corrosion protection and protective coatings. However, the selected sol-gels should have a satisfying UV photosensitivity to allow the photolithography through laser exposure, but also high transparency coupled with important refractive indices fostering the best performances regarding the light transport on long-distance. The choice of the inscription technique is also discussed in terms of flexibility, and a selection is made between conventional amplitude mask techniques and the direct writing approach. The characterization of the different sol-gel guides is presented, namely their optical properties (refractive index, mode confinement) and thermal behaviors. Finally, the coupling of the sol-gel waveguide with a light source and a detector are studied, and further investigations carried out regarding preliminary results on the impact detection while injection in a waveguide grid is demonstrated, showing that these 2D sol-gel photonic sensors can operate as SHM tools. 


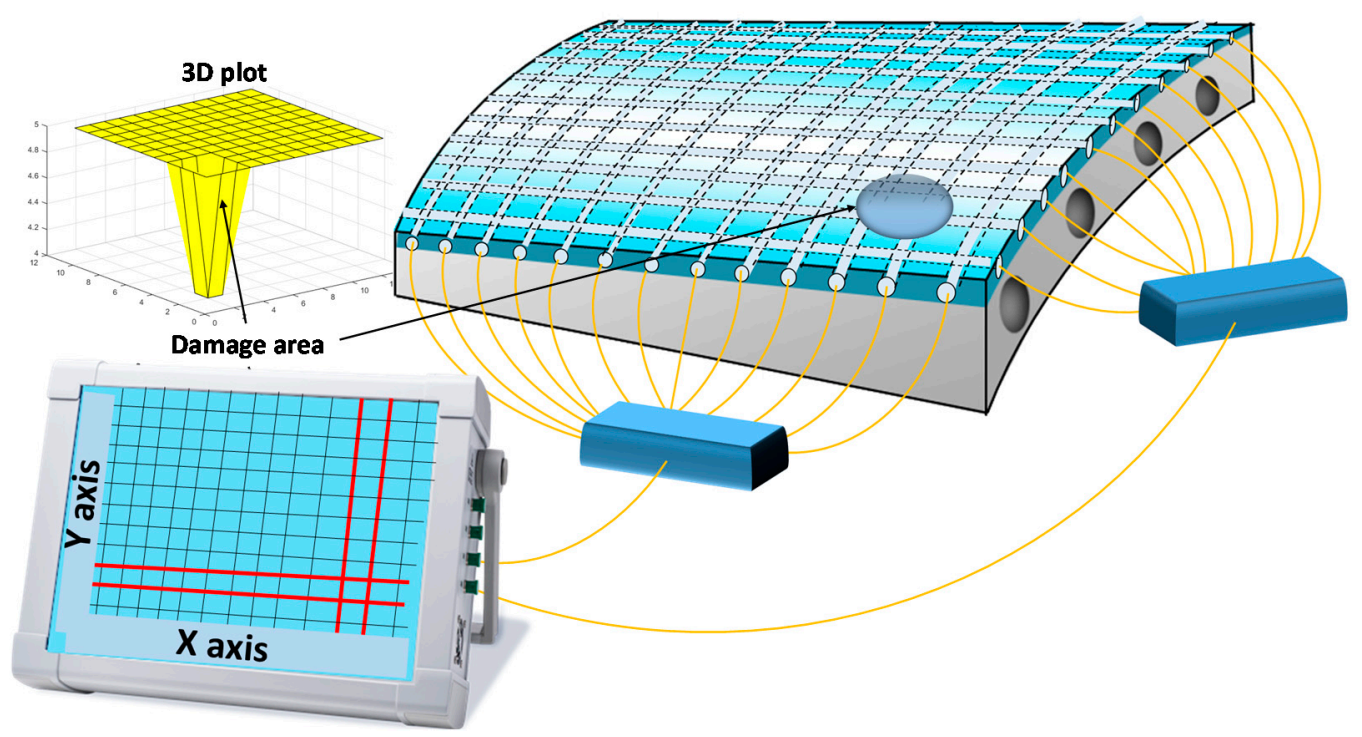

Figure 1. Final architecture of the 2D sol-gel matrix sensor for damage detection. The sensor is based on a grid of optical waveguides. An impact on the plane leads to the degradation or the rupture of one or more waveguides. Thanks to the particular 2D structure of the sensing material, the identification of the impacted damage allows the damage localization.

\section{Materials and Methods}

To create the waveguide sensors, two homemade organic-inorganic solutions are synthesized and used as the core and the cladding, respectively, whose preparations are shown in Figure 2. The chemical reagents presented in this manuscript were provided by Sigma-Aldrich and used without purification procedures. The developed sol-gel acting as the waveguide core is composed of $\mathrm{TiO}_{2}-\mathrm{SiO}_{2}$. More specifically, this latter results from the combination of titanium (IV) isopropoxide (TIPT, 97\%), 3-(trimethoxysilyl)propyl methacrylate (MAPTMS) and 2-(methacryloyloxy)ethyl acetoacetate (AEM), working as the chelating agent. First preliminary hydrolysis of the silica precursor (MAPTMS) is then performed by adding $\mathrm{HCl}(0.01 \mathrm{M})$ and denoted as solution 1 (Figure 2a), while AEM is incorporated with TIPT (solution 2). These two solutions are mixed, and after a stirring period of $1 \mathrm{~h}$, purified water is incorporated to have access to full hydrolysis. Moreover, to enhance the photosensitivity of the layers exposed to UV radiation, a photoinitiator (2,2-dimethoxy-2-phenylacetophenone, DMPA) is added in the form of $0.7 \mathrm{wt} \%$. Regarding this $\mathrm{TiO}_{2}-\mathrm{SiO}_{2}$ sol-gel, the resulting molar ratios $\mathrm{Si}$ :Ti:AAEM of the precursors mentioned above are fixed at 10:10:5.5. The second sol-gel, acting as the cladding, is a hybrid sol-gel composed of $\mathrm{ZrO}_{2}-\mathrm{SiO}_{2}$ (Figure 2b). The material synthesis is rather similar to the $\mathrm{TiO}_{2}-$ $\mathrm{SiO}_{2}$ sol insofar as MAPTMS is still used as silica precursor for which partial hydrolysis of MAPTMS is also reached using $\mathrm{HCl}$ (solution 3). Additionally, zirconium (IV) propoxide $\left(\mathrm{Zr}(\mathrm{OPr})_{4}, 70 \%\right.$ in 1-propanol) is chelated with methacrylic acid (MAA) and is denoted as solution 4 (Figure 2b). Solution 4 is then mixed with solution 3, and water is added to the mixture to get total hydrolysis and condensation. Finally, as explained regarding the $\mathrm{TiO}_{2}-\mathrm{SiO}_{2}$ sol, the photosensitivity of the $\mathrm{ZrO}_{2}-\mathrm{SiO}_{2}$ is enhanced by the incorporation of DMPA in the form of $1.1 \mathrm{wt} \%$. For this particular mixture, the molar ratios of Si:Zr:MAA are 10:3:3. It is to note that after the material synthesis, both mixtures $\left(\mathrm{TiO}_{2}-\mathrm{SiO}_{2}\right.$ and $\mathrm{ZrO}_{2}-\mathrm{SiO}_{2}$ ) are filtered at $0.2 \mu \mathrm{m}$, outgassed under nitrogen and aged for 2 days before use. Moreover, the different sol-gels can make an organic and mineral network after UV polymerization. Those materials act as negative photoresists meaning that the zones exposed to UV photons are resistant to any alcohol attack (ethanol, butanol, propanol, etc.) due to the photopolymerization, while the unexposed areas are dissolved and removed during the development process. 
(a)

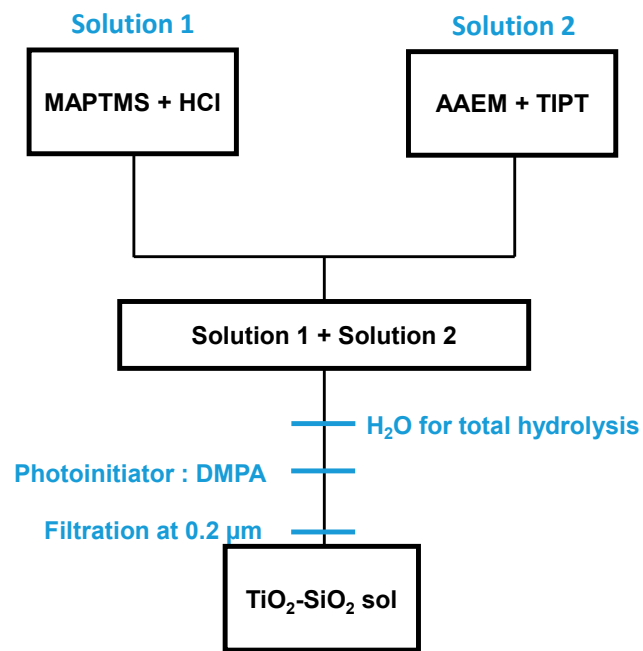

(b)

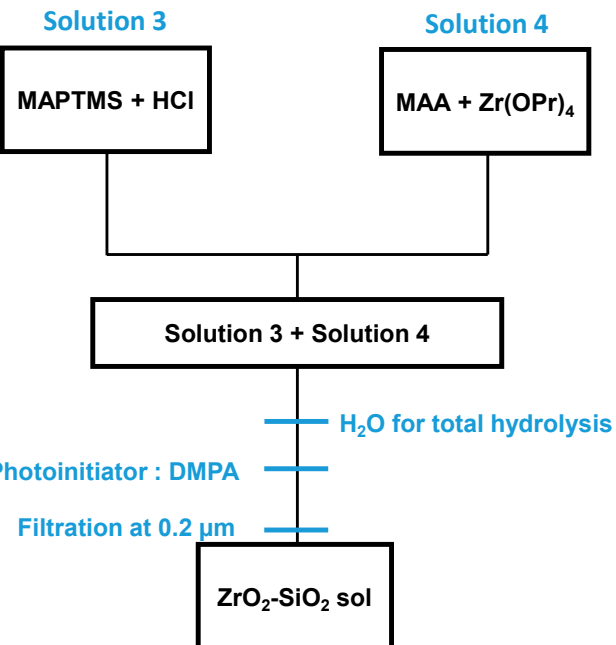

Figure 2. Preparation of the different organic-inorganic sol-gel solutions. Material synthesis of (a) $\mathrm{TiO}_{2}-\mathrm{SiO}_{2}$ and (b) $\mathrm{ZrO}_{2}-\mathrm{SiO}_{2}$ sols. In both cases, a photoinitiator (DMPA) is added to induce the start of UV-polymerization reactions.

The different thin layers were coated in a cleanroom at fixed temperature and hygrometry using either the spin or dip-coating technique on a soda-lime glass substrate. This particular substrate was chosen so that its optical properties, namely in terms of refractive index, are similar to the $\mathrm{ZrO}_{2}-\mathrm{SiO}_{2}$ cladding. A more detailed discussion is given in Section 3.4. The first coating approach is based on a rotating plate whose angular speed (Rotations Per Minute, RPM) is tunable, allowing the deposition of sol-gel on the substrate through centrifugal force. The second deposition (dip) process is based on the immersion of the substrate, and the layer is deposited while it is pulled up at a constant speed. In both cases, the deposition speed strictly determines the layer thicknesses and is further investigated in the following sections. The resulting deposited layers are pre-baked at $60{ }^{\circ} \mathrm{C}$ for $5 \mathrm{~min}$, a necessary step so as to evaporate the different solvents and to achieve a film pre-densification. The layers are then exposed to UV photons using different photolithography approaches. The first one, largely employed over the years and shown in Figure $3 \mathrm{a}$, consists of using a $10 \mathrm{~cm}$ squared photomask made of chromium where several slits are present ranging from $3 \mu \mathrm{m}$ to $15 \mu \mathrm{m}$ with a fixed length of roughly $7 \mathrm{~cm}$. The UV exposure is made using a UWAVE lamp emitting at $365 \mathrm{~nm}$, for which it is possible to control the fluence. Another UV exposure is investigated to create photo-induced patterns using the Dilase 750 facility [18] (Kloé company, Montpellier, France), a photolithography machine based on the direct writing technique whose description is given in Figure $3 \mathrm{~b}$. To this aim, a CW laser (Kloé company, Montpellier, France) delivering UV photons at $375 \mathrm{~nm}$ $(26 \mathrm{~mW})$ is focused on hybrid $\mathrm{SiO}_{2}-\mathrm{TiO}_{2}$ thin layers through a long-distance $\times 10$ semiapochromatic microscope objective (numerical aperture: 0.3 ). A computer-controlled XY stage is used to translate the substrate (circular, rectangle, square) over several tens of $\mathrm{cm}$ with a resolution and repeatability of $100 \mathrm{~nm}$. Thanks to the software dedicated to pattern creation, it is possible to have more important flexibility in terms of structures than those that can be manufactured using the amplitude mask method. Moreover, it is possible to control the laser power and the scanning speed, thus determining the lateral dimensions of the photonic devices presented in the following sections. An optical density (OD) can also be added along the optical path to attenuate the laser power (NE10A, OD =1, Thorlabs). 
(a)
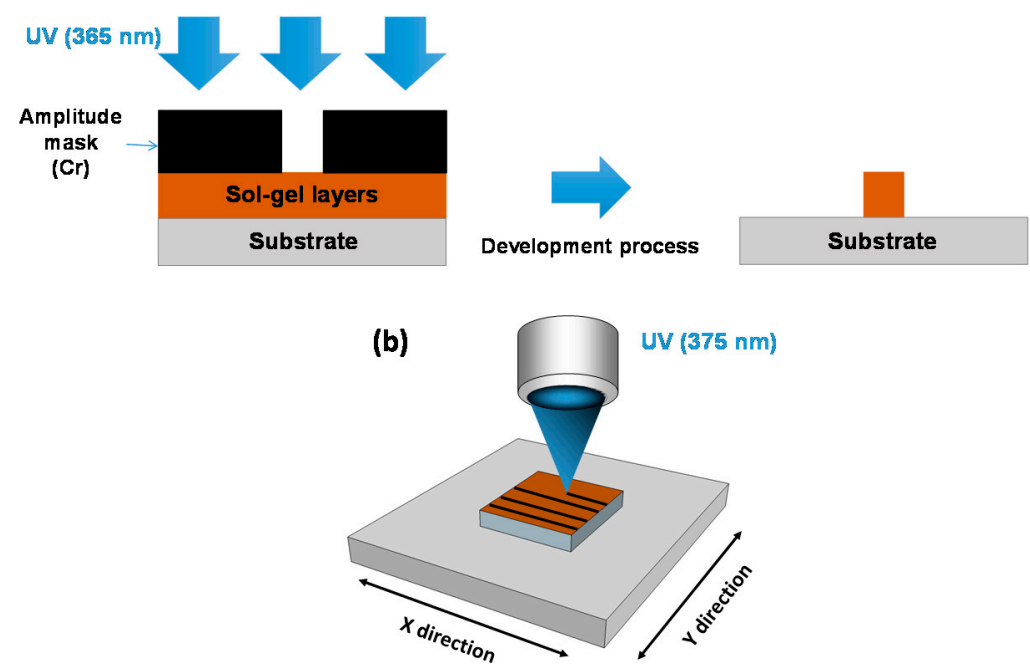

Figure 3. Example of the photolithography processes used for the layer structuration. (a) Photolithography by photomask on an organic-inorganic layer. (b) Principle of the direct writing technique (Dilase 750 from Kloé company, Montpellier, France). A laser beam is focused on the hybrid thin films. The structures are created by the translation of the stages in the $X$ and $Y$ directions while the laser beam is fixed. The black lines on the layer represent the UV photopolymerized exposed regions.

After the UV photolithography process, which can be achieved by the amplitude mask or by direct writing, developing the full device is obtained by an immersion in butanol where the unpolymerized parts are removed. Additionally, a post-bake at $90{ }^{\circ} \mathrm{C}$ for $30 \mathrm{~min}$ is performed for permanent strengthening of the films and the mineral network, thus stabilizing the structure and improving the thermal stability of the layers. The characterization of the photopolymerized structures is performed using an optical microscope (Axio imager M1m, Zeiss company) in reflection mode and a Dektak profilometer (Bruker company, Billerica, MA, USA) with a stylus force (SF) of $10 \mathrm{mg}$ or $15 \mathrm{mg}$ depending on the application to quantify the shapes and thicknesses, respectively. The refractive index (n) measurements of the insolated layers were carried out using a phase-modulated spectroscopic ellipsometer (UVISEL from Horiba Jobin Yvon, Kyoto, Japan), operating in the 300 to $1800 \mathrm{~nm}$ wavelength range with a $5 \mathrm{~nm}$ resolution. This technique is based on modifying light polarization after reflection, and a largely detailed description can be found elsewhere [19]. Additionally, the different architectures were tested in terms of light propagation and their behavior under damages investigated by an experimental setup. This latter is composed of a Corning single-mode fiber (SMF28) with a core diameter of $8 \mu \mathrm{m}$ injecting light $(638 \mathrm{~nm}$ and $1550 \mathrm{~nm}$ ) into the different waveguides through a butt-coupling configuration. Two cameras coupled with objectives are used. The first one allows imaging the guided mode at the output, while the second allows having a top-view of the connection between the SMF28 and the $\mathrm{TiO}_{2}-\mathrm{SiO}_{2}$ waveguides, thus optimizing the light injection inside this latter.

\section{Results and Discussion}

\subsection{Amplitude Mask Method and Thicknesses Characterization}

The following part aims at checking the photosensitivity of both $\mathrm{TiO}_{2}-\mathrm{SiO}_{2}$ and $\mathrm{ZrO}_{2}-$ $\mathrm{SiO}_{2}$ layers as well as creating the first $\mathrm{TiO}_{2}-\mathrm{SiO}_{2}$ core structure using the well-known photomask amplitude technique widely deployed regarding the standard photolithography processes [20,21]. As mentioned previously, it is possible to have access to the fluence needed for a full polymerization. Varying the exposure time and the irradiance gave an idea about the minimal fluence required to create the $\mathrm{TiO}_{2}-\mathrm{SiO}_{2}$ structures. To this aim, we performed several UV exposures (at $365 \mathrm{~nm}$ ) with fluences ranging from 54 to $180 \mathrm{~J} / \mathrm{cm}^{2}$, as described in Table 1, for sol-gel deposited using the spin coating approach at 6000 RPM. After the development process in butanol, we can distinguish three interaction regimes. 
Table 1. $\mathrm{TiO}_{2}-\mathrm{SiO}_{2}$ photosensitivity between 54 and $180 \mathrm{~J} / \mathrm{cm}^{2}$ through amplitude mask method.

\begin{tabular}{cc}
\hline Fluence $\left(\mathbf{J} / \mathrm{cm}^{2}\right)$ & Polymerization \\
\hline 54 & No \\
72 & Partial \\
90 & Full \\
108 & Full \\
144 & Full \\
180 & Full \\
\hline
\end{tabular}

The first regime is referring to the low fluences. For instance, after a $54 \mathrm{~J} / \mathrm{cm}^{2}$ exposure, the structure is not present, highlighting the fact that the polymerization and the cross-linking effect are not sufficient: the exposed part does not resist any alcohol attack. Increasing the fluence leads to the second regime where a first partial polymerization is achieved. Under this condition, the remaining structure after the development process is partially obtained and seems not sufficiently repeatable. A full line is present for higher fluences $\left(90 \mathrm{~J} / \mathrm{cm}^{2}\right)$ after the development in a reproducible and reliable way. Interestingly, one could note that increasing the fluence does not impact the structure quality since no calcination occurs.

To check the quality of the photo-induced $\mathrm{TiO}_{2}-\mathrm{SiO}_{2}$ patterns, we performed a series of microscope observations (reflection mode $\times 20$ ), as illustrated in Figure 4, showing the different structures obtained using three different slits of $15 \mu \mathrm{m}$ (Figure $4 \mathrm{a}$ ), $8 \mu \mathrm{m}$ (Figure $4 \mathrm{~b}$ ) and $3 \mu \mathrm{m}$ (Figure $4 \mathrm{c}$ ) after being irradiated with a $180 \mathrm{~J} / \mathrm{cm}^{2}$ fluence. It shows that the widths of those structures are regular and ranging from $22 \mu \mathrm{m}$ to $7 \mu \mathrm{m}$. In addition to these observations, a profilometer measurement (Figure 4d) is carried out on the pattern illustrated in Figure 4a. The layers being deposited at $6000 \mathrm{RPM}$, it is possible to have access to a thickness of roughly $3.5 \mu \mathrm{m}$ with a relatively top-hat profile. It is important to mention that the width obtained with the profilometer measurement seems not to fit with the one obtained regarding the microscope image given in (a). This behavior is normal because the resulting profile is a convolution between the real profile and the stylus shape probing the sample.
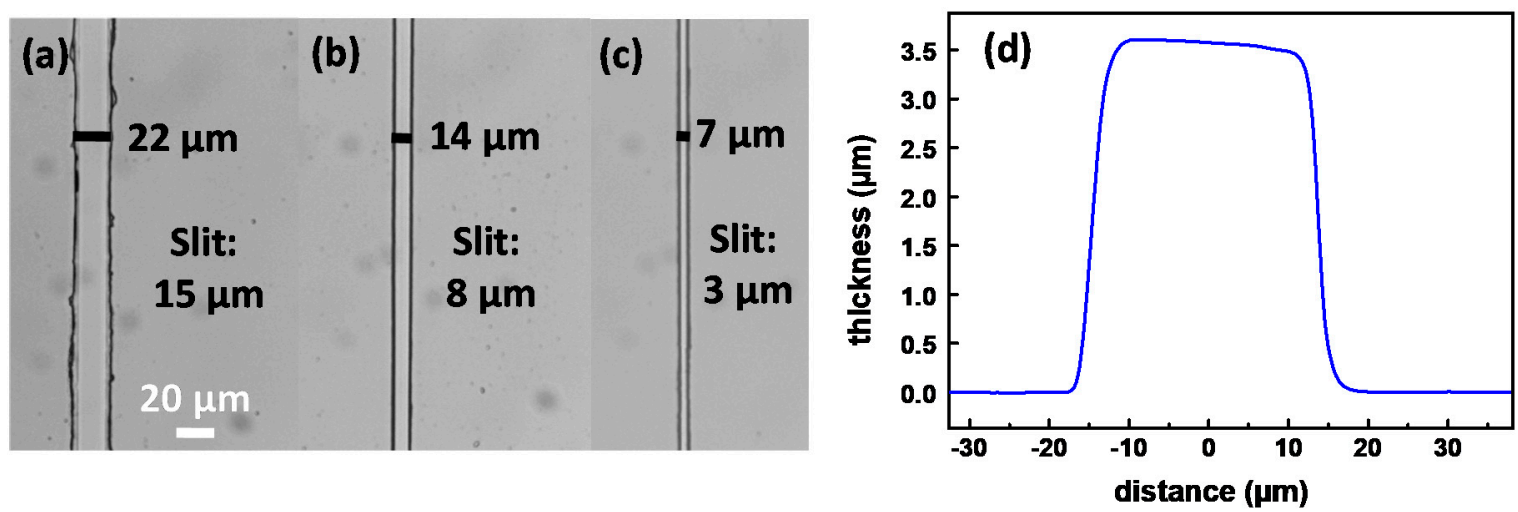

Figure 4. $\mathrm{TiO}_{2}-\mathrm{SiO}_{2}$ patterns obtained using the amplitude mask with different slits at $15 \mu \mathrm{m}, 8 \mu \mathrm{m}$ and $3 \mu \mathrm{m}$. Microscope observations (reflection x20) of (a) line obtained with a slit of $15 \mu \mathrm{m}$ in width, (b) line obtained with a slit of $8 \mu \mathrm{m}$ and (c) line obtained with a slit of $3 \mu \mathrm{m}$. (d) Profilometer measurement of (a).

As mentioned in Section 2, the speed deposition strongly determines the layer thickness. Consequently, the knowledge (and control) of this parameter is of great importance regarding creating photonic devices. To have a precise idea of this quantity, we investigated the thickness of $\mathrm{TiO}_{2}-\mathrm{SiO}_{2}$ and $\mathrm{ZrO}_{2}-\mathrm{SiO}_{2}$ sol-gels. To this aim, the layers were exposed to UV photons at a $180 \mathrm{~J} / \mathrm{cm}^{2}$ fluence to ensure a high polymerization rate and thermally treated following the procedure described in Section 2. The resulting thicknesses are shown in Figure 5a,b, using the spin and dip approaches, respectively. In both cases, the 
$\mathrm{ZrO}_{2}-\mathrm{SiO}_{2}$ layers (black dotted curve) are thicker compared with the $\mathrm{TiO}_{2}-\mathrm{SiO}_{2}$ ones (red squared curve), with values ranging from $12 \mu \mathrm{m}$ to $4.7 \mu \mathrm{m}$ between 1000 and 6000 RPM (Figure 5a). Using the dip-coating approach, thicknesses of $3 \mu \mathrm{m}$ and roughly $6.5 \mu \mathrm{m}$ can be reached for the two extremal translation speeds $(1.5 \mathrm{~cm} / \mathrm{min}$ and $7 \mathrm{~cm} / \mathrm{min})$ as observed in Figure $5 \mathrm{~b}$. The $\mathrm{TiO}_{2}-\mathrm{SiO}_{2}$ behavior was also investigated, and lower thicknesses can be obtained ranging from $9 \mu \mathrm{m}$ to $3.5 \mu \mathrm{m}$ and $2 \mu \mathrm{m}$ to $4.9 \mu \mathrm{m}$ for the spin (a) and dip (b) coating, respectively. The fact that higher thicknesses are achieved for $\mathrm{ZrO}_{2}-\mathrm{SiO}_{2}$ layers is explained by a more viscous solution compared with the core solution. Interestingly, it is important to mention that the UV polymerization is not impacted by large thicknesses $(>10 \mu \mathrm{m})$ since the area exposed to UV is still present after the development process. This result clearly shows a high UV penetration depth so that we can obtain high-aspect-ratio structures.
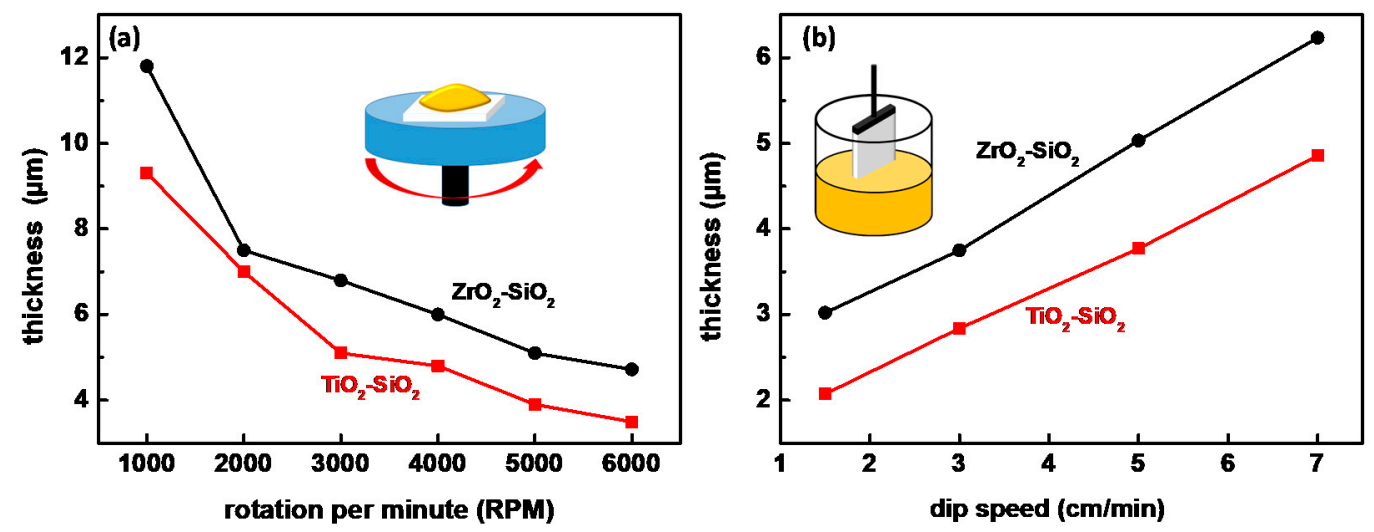

Figure 5. Investigation of $\mathrm{TiO}_{2}-\mathrm{SiO}_{2}$ (red squared curve) and $\mathrm{ZrO}_{2}-\mathrm{SiO}_{2}$ (black dotted curve) thicknesses using the spin coating (a) and the dip coating (b) methods.

The $\mathrm{TiO}_{2}-\mathrm{SiO}_{2}$ films were evaluated in terms of photosensitivity and thicknesses. As the primary goal is creating a 2D matrix sol-gel waveguides, we checked the feasibility of making a $\mathrm{TiO}_{2}-\mathrm{SiO}_{2}$ structure grid using the amplitude mask approach on a $4.5 \mathrm{~cm}$ squared substrate. The corresponding results are presented in Figure 6. Crossed waveguides can be obtained using a two steps approach. The first one consists of patterning a series of structures in a given direction at a $180 \mathrm{~J} / \mathrm{cm}^{2}$ fluence. The second step is realized by rotating the photomask at $90^{\circ}$ followed by a second UV insolation. After the development process, a $\mathrm{TiO}_{2}-\mathrm{SiO}_{2}$ grid is photoetched as observed in Figure 6, where particular attention is given to the crossed area exposed to a total fluence of $360 \mathrm{~J} / \mathrm{cm}^{2}$. Interestingly, this region seems unaffected by the double laser-exposure leading to a uniform $\mathrm{TiO}_{2}-\mathrm{SiO}_{2}$ architecture.

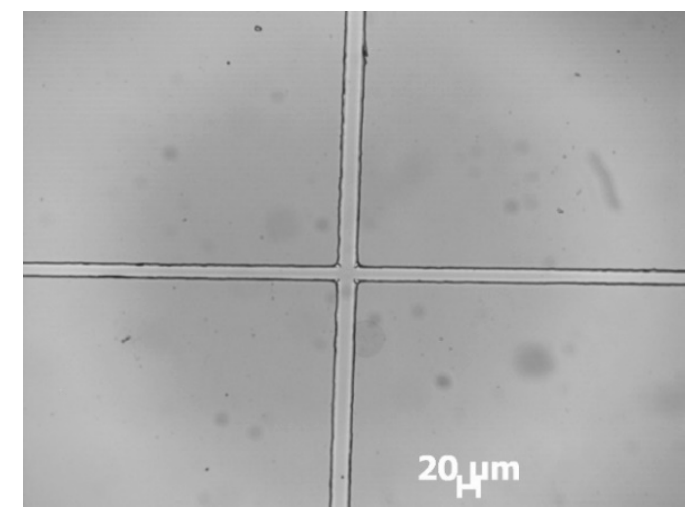

Figure 6. $\mathrm{TiO}_{2}-\mathrm{SiO}_{2}$ grid observed using an optical microscope in a reflection mode $(\times 20)$. The crossed $\mathrm{TiO}_{2}-\mathrm{SiO}_{2}$ area is not affected by the double exposure $\left(360 \mathrm{~J} / \mathrm{cm}^{2}\right)$. 
The results clearly show that both sol-gels are photosensitive with respect to UV photons $(365 \mathrm{~nm})$. It is evident that creating $\mathrm{TiO}_{2}-\mathrm{SiO}_{2}$ photonic components is possible using the well-known amplitude mask technique providing the desired shapes with relatively top-hat profiles. However, their dimensions are restricted by the photomask length $(10 \mathrm{~cm})$, the slit size $(7 \mathrm{~cm})$ and by the UV source dimensions (and homogeneity), meaning that this technique cannot be deployed on larger surfaces as it is required in the ADD-ON project framework.

\subsection{Direct Writing Technique}

Alternatively to the amplitude mask method, the direct writing technique was also investigated using the Dilase 750 facility, where photolithography processes can be achieved on a $40 \mathrm{~cm}$ squared substrate. Even though the direct writing technique was already discussed in the literature [22,23], it seems that photolithography on large substrates is not clearly reported. Insofar as the $\mathrm{TiO}_{2}-\mathrm{SiO}_{2}$ films correspond to the core, the behavior of this sol-gel is of great importance regarding the microstructuration using the direct writing approach. We present in Figure 7 the results concerning creating $\mathrm{TiO}_{2}-\mathrm{SiO}_{2}$ structures using this technique. To this purpose, we checked the feasibility of making lines for several scanning speeds (ranging from $200 \mu \mathrm{m} / \mathrm{s}$ to $10 \mathrm{~mm} / \mathrm{s}$ ) and powers ranging from 1\% to 100\% of the total laser power. Through Figure 7a, we can see that the sol-gel is still photosensitive to a $375 \mathrm{~nm}$ wavelength and that a full structure can be photo-etched using $10 \%$ of the laser power. More specifically, a full structure is obtained between 1\% and $15 \%$ of the total laser power. However, for $20 \%$ and higher accumulated doses (i.e., high-power and low scanning speed), the sol-gel is overexposed, resulting in the calcination of the $\mathrm{TiO}_{2}-\mathrm{SiO}_{2}$ layer as observed in Figure $7 \mathrm{~b}$, where a trace is obtained at 30\% and a scanning speed of $200 \mu \mathrm{m} / \mathrm{s}$. Due to the high flexibility of the direct writing technique, it is possible to have access to the fabrication of more exotic architectures with the highest resolutions than the ones obtained by the photomask. The potentiality of this approach can be observed through Figure 7c, where a University Jean Monnet logo is given. This later is achieved by microstructuration of a $\mathrm{TiO}_{2}-\mathrm{SiO}_{2}$ sol-gel and has a height of $420 \mu \mathrm{m}$.

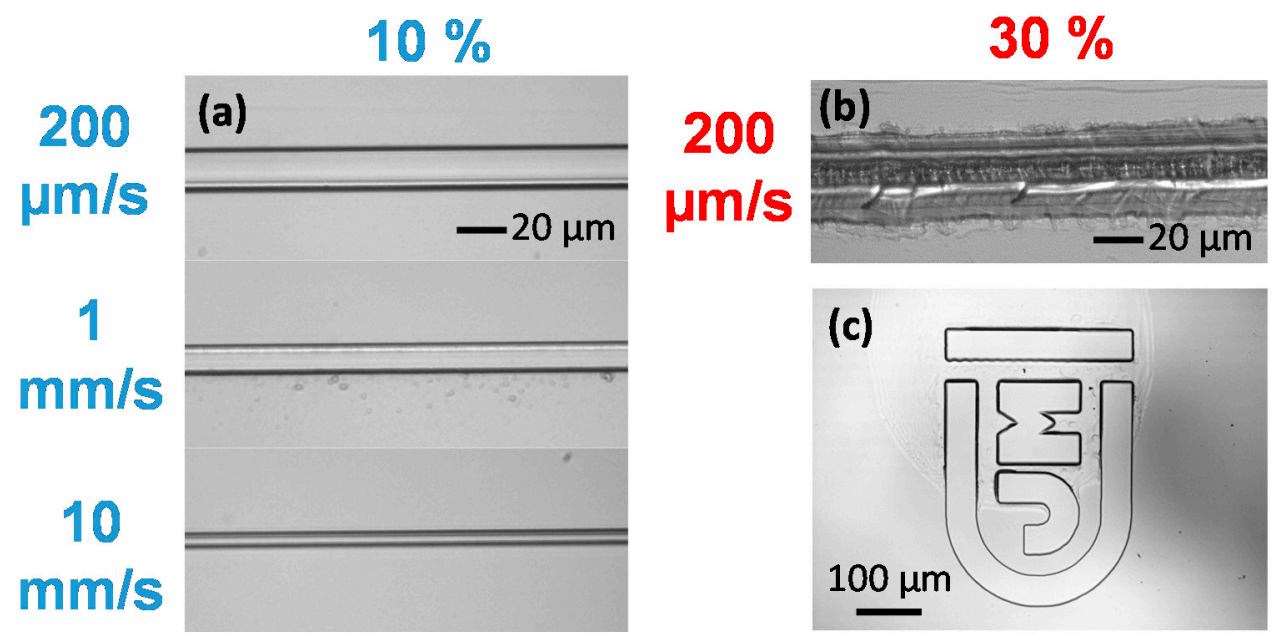

Figure 7. Structures obtained by the direct writing technique showing (a) lines obtained at $10 \%$ and for different scanning speed $(200 \mu \mathrm{m} / \mathrm{s}, 1$ and $10 \mathrm{~mm} / \mathrm{s})$, (b) calcinated trace induced at 30\% and $200 \mu \mathrm{m} / \mathrm{s}$ and (c) Jean Monnet University logo with a $420 \mu \mathrm{m}$ size in height.

The accumulated dose, controlled through the laser power and the scanning speed, strongly determines the structure width at $10 \%$ and $200 \mu \mathrm{m} / \mathrm{s}, 1$ and $10 \mathrm{~mm} / \mathrm{s}$. This aspect can be observed in Figure 7a, revealing that the line is thinner by increasing the stage velocity. Particular attention is given to this behavior, as shown in Figure 8a, where the structure width is investigated for powers and scanning speeds ranging from $1 \%$ to $15 \%$ 
and $200 \mu \mathrm{m} / \mathrm{s}$ to $10 \mathrm{~mm} / \mathrm{s}$, respectively. Interestingly, at $1 \%$ of the laser power, the structure remains present after the development in butanol, revealing that the UV polymerization is already sufficient to create sol-gel devices. The graph provides a clear indication that changing those parameters allows tuning the width of the photo-induced patterns. For example, it is possible to reach widths with various sizes comprise between $20 \mu \mathrm{m}$ and $4 \mu \mathrm{m}$. A profilometer measurement is also given in Figure $8 \mathrm{~b}$ revealing the shape of a structure written at $10 \%$ and $200 \mu \mathrm{m} / \mathrm{s}$. This latter seems coherent with the ones obtained with the amplitude mask technique (Figure 4d), where top-hat architectures are induced due to a uniform intensity profile of the UWAVE lamp. However, the profile shown in Figure $8 \mathrm{~b}$ and achieved by the direct writing method is less flat. This behavior is normal since the UV laser beam cross-section is Gaussian.
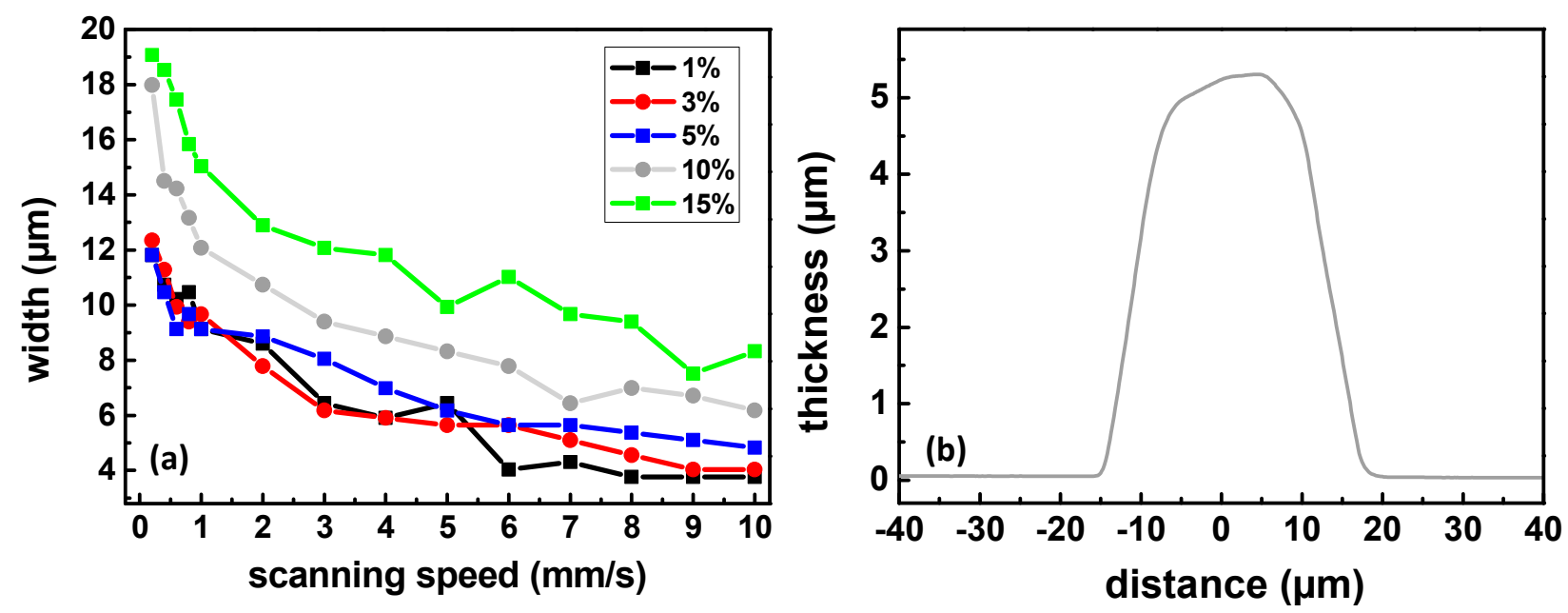

Figure 8. Characterization of the photo-induced patterns using the Dilase 750 facility. (a) Width of the structures as a function of the scanning speed for powers ranging from $1 \%$ and $15 \%$ and $(\mathbf{b})$ profile obtained for a line written at $10 \%$ and $200 \mu \mathrm{m} / \mathrm{s}$.

The direct writing method seems to be more flexible compared with the photomask lithography. In addition, it is possible to achieve photolithography on a very large substrate, a crucial point regarding the ADD-ON project. To this aim, a $30 \mathrm{~cm}$ per $35 \mathrm{~cm} \mathrm{TiO}{ }_{2}-\mathrm{SiO}_{2}$ grid architecture is obtained, and an image is reported in Figure 9a. This latter is induced at $10 \%$ and $3 \mathrm{~mm} / \mathrm{s}$ by creating a line array in a given direction, while a second array is performed in a perpendicular direction and superimposed to the first one. The photoinduced device comprises 62 lines separated by a $1 \mathrm{~cm}$ distance, as shown in Figure $9 \mathrm{~b}$. This result highlights two points: the $\mathrm{TiO}_{2}-\mathrm{SiO}_{2}$ sol-gel can be uniformly deposited on a $30 \mathrm{~cm} \times 35 \mathrm{~cm}$ substrate, and that photolithography processes can be easily performed on large size by the direct writing technique. Moreover, a microscope image is shown focusing on the crossed area (Figure 9c). As expected, this double-exposed zone is unaffected by the two consecutive irradiations. 

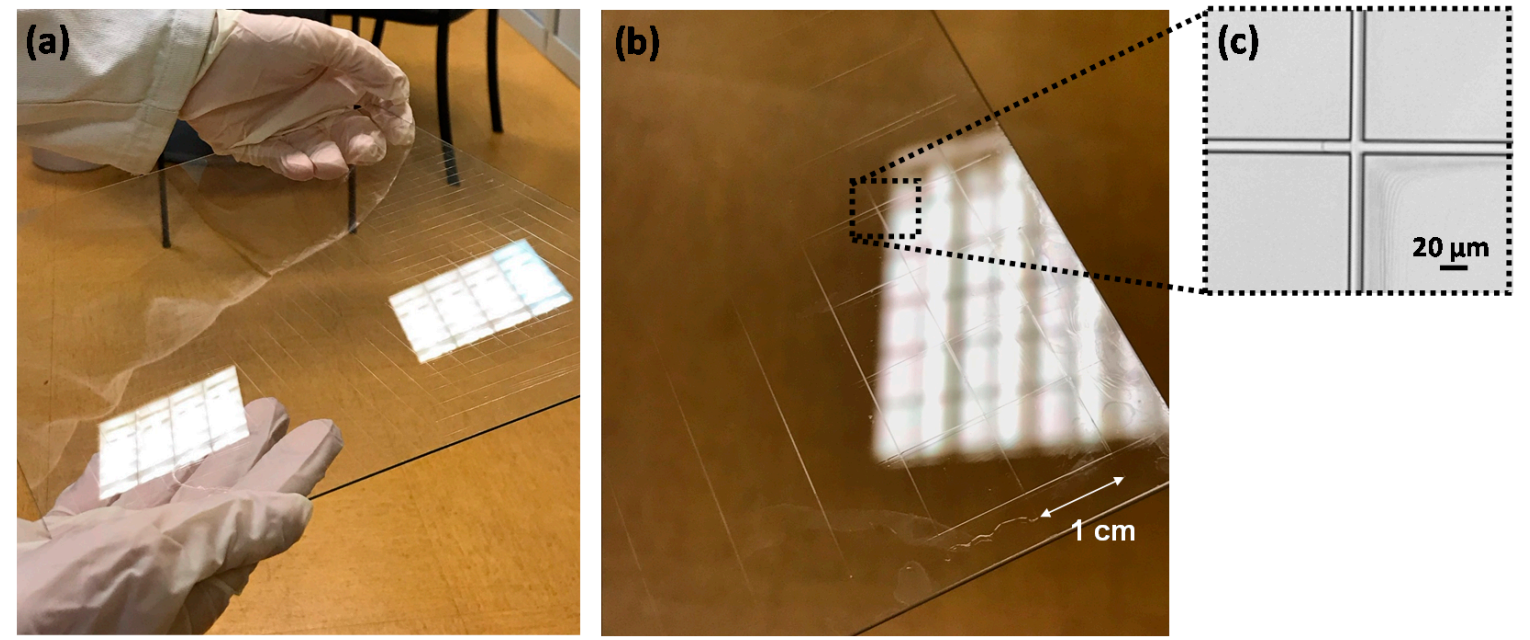

Figure 9. $\mathrm{TiO}_{2}-\mathrm{SiO}_{2}$ grid architecture on a large substrate composed of 62 guides. (a) Overview of the sensor, (b) corresponding zoom showing the $1 \mathrm{~cm}$ separation between two consecutive lines and (c) microscope image of the doubled exposed zone.

\subsection{Creation of the Full Device: $\mathrm{TiO}_{2}-\mathrm{SiO}_{2}$ Core and $\mathrm{ZrO}_{2}-\mathrm{SiO}_{2}$ Cladding}

In the previous section, we focused our work on the microstructuration of $\mathrm{TiO}_{2}-\mathrm{SiO}_{2}$ layers using the direct writing technique. After the development in butanol, the resulting structure is composed of a $\mathrm{TiO}_{2}-\mathrm{SiO}_{2}$ sol-gel waveguide deposited on a soda-lime glass substrate and surrounded by air, as observed in Figure 10a. Additionally, a $\mathrm{ZrO}_{2}-\mathrm{SiO}_{2}$ cladding can also be added and acts as a protective layer (Figure 10b). For this latter, the $\mathrm{TiO}_{2}-\mathrm{SiO}_{2}$ layer, still deposited on soda-lime glass, is buried and surrounded by a $\mathrm{ZrO}_{2}-\mathrm{SiO}_{2}$ coating. This approach allows improving the mechanical resistance of the architecture [21]. It is to note that these two approaches (with and without cladding) are investigated in terms of guiding properties.

(a)

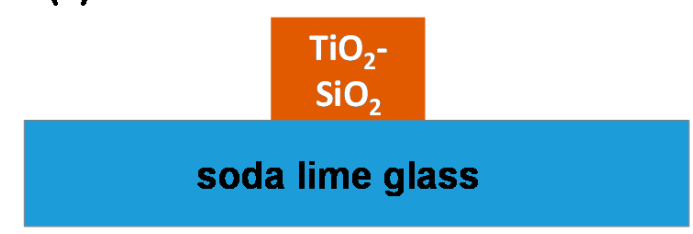

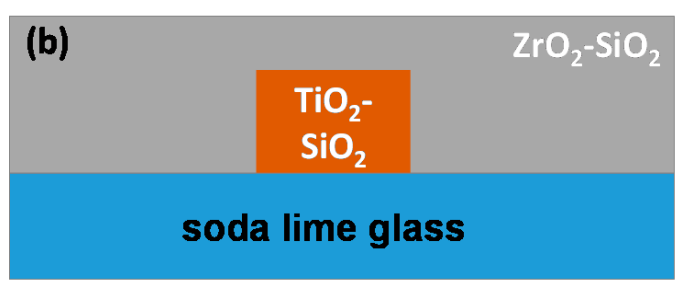

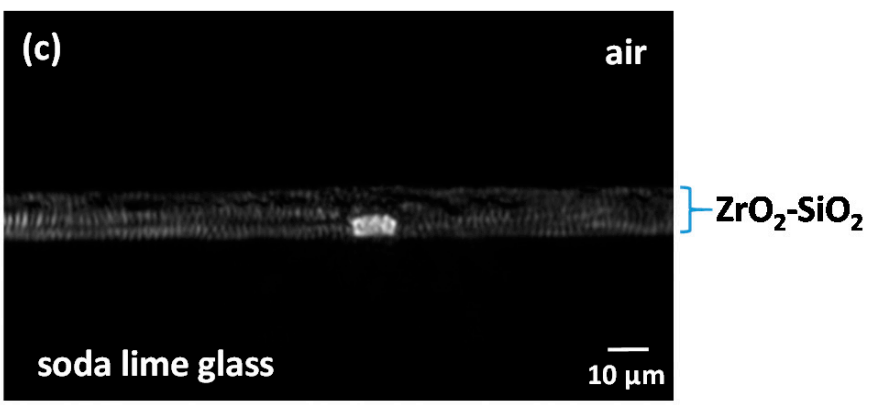

Figure 10. Two configurations of the photonic device deposited on soda-lime glass. (a) $\mathrm{TiO}_{2}-\mathrm{SiO}_{2}$ core without cladding and surrounded by air. (b) $\mathrm{TiO}_{2}-\mathrm{SiO}_{2}$ core buried in a $\mathrm{ZrO}_{2}-\mathrm{SiO}_{2}$ coating and (c) output light of the $\mathrm{TiO}_{2}-\mathrm{SiO}_{2}$ core waveguide with $\mathrm{ZrO}_{2}-\mathrm{SiO}_{2}$ cladding obtained experimentally.

To create the architecture reported in Figure 10b, a two-step approach is performed. The first one relies on creating the core using the direct writing approach, as already 
discussed in Section 3.2. More specifically, the $\mathrm{TiO}_{2}-\mathrm{SiO}_{2}$ layer is deposited at $4000 \mathrm{RPM}$ to reach a film thickness of $5 \mu \mathrm{m}$. A pre-bake is realized at $60^{\circ} \mathrm{C}$ for $5 \mathrm{~min}$. Moreover, a core of roughly $10 \mu \mathrm{m}$ is induced using the Dilase 750 facility, and after the development process, the $\mathrm{TiO}_{2}-\mathrm{SiO}_{2}$ core is heated at $90{ }^{\circ} \mathrm{C}$ for $30 \mathrm{~min}$. The second step consists of the addition of the $\mathrm{ZrO}_{2}-\mathrm{SiO}_{2}$ protective layer. The film thickness should be high enough so that the core remains totally buried. Through Figure 5, we have seen the dependence of the thickness concerning the angular speed. Consequently, the protective layer was spin-coated at $1000 \mathrm{RPM}$ to ensure a $12 \mu \mathrm{m}$ thickness. Obviously, below this value, the resulting layers are thicker but nonhomogeneous. The films were then baked at $90{ }^{\circ} \mathrm{C}$ for $30 \mathrm{~min}$, and the photopolymerization is achieved using the UWAVE lamp. Interestingly, despite the two thermal treatments at $90{ }^{\circ} \mathrm{C}$ and the double insolation provided by the Dilase 750 and the UWAVE lamp, respectively, the $\mathrm{TiO}_{2}-\mathrm{SiO}_{2}$ core is unaffected. This thermal resistance can be explained by the presence of the mineral network, as mentioned by others authors [21]. A cross-sectional view of the full architecture is shown in Figure 10c, clearly indicating that the $\mathrm{TiO}_{2}-\mathrm{SiO}_{2}$ core is totally buried.

\subsection{Refractive Index Measurements}

One of the primary goals of the UV photolithography is the optimization of the refractive index contrast $(\Delta \mathrm{n})$ between the core and the surrounding environment (air, substrate, protective layer . . . , ) fostering the best performances possible of sol-gel photonic devices in terms of low losses and mode confinement. Thus, it is essential to quantify (and even control) the refractive index of the insolated sol-gel thin films. Moreover, the refractive index of the layer can be adjusted by varying the molar ratio of the precursors used during the preparation [24]. This tunability provides the best tradeoff while considering the desired application. For example, it is possible to achieve guiding properties with low losses of $0.5 \mathrm{~dB} / \mathrm{cm}$ at $1310 \mathrm{~nm}$ for organic-inorganic sol-gel material with a $\Delta \mathrm{n}$ of $10^{-2}$ [16], while other authors show that an index contrast of $1.3 \times 10^{-2}$ is sufficient to operate at $1550 \mathrm{~nm}$ with losses of $0.1 \mathrm{~dB} / \mathrm{cm}$ [20]. The refractive indices of the $\mathrm{TiO}_{2}-\mathrm{SiO}_{2}$ and $\mathrm{ZrO}_{2}-$ $\mathrm{SiO}_{2}$ thin films were determined by the ellipsometry approach. Recall that these layers were submitted to UV radiation and thermally treated, as described in Section 2. For these particular measurements, it is essential to have a substrate with different optical properties (refractive index) compared with the sol-gel films to be characterized to clearly discriminate the wafer contribution from the layer. The two different films were then deposited on a Si substrate, ideal for ellipsometric measurements insofar as refractive indices between 4.97 at $300 \mathrm{~nm}$ [25] and 3.4 in the far-Infrared (IR) region [26] are found.

The results presented in Figure 11 reveal the refractive indices for both layers: $\mathrm{TiO}_{2}-$ $\mathrm{SiO}_{2}$ (red line) and $\mathrm{ZrO}_{2}-\mathrm{SiO}_{2}$ (black line). These data are to be understood from the perspective of photonic device sensors manufacturing. Indeed, through this graph, it is evident that the refractive index of $\mathrm{TiO}_{2}-\mathrm{SiO}_{2}$ material is higher than those obtained with the $\mathrm{ZrO}_{2}-\mathrm{SiO}_{2}$ film. More specifically, three wavelengths $(630,810$ and $1550 \mathrm{~nm}$ ) were pointed out corresponding to spectral domains of interest for the sensing. We can observe that we have access to refractive index ranging from $1.580(630 \mathrm{~nm})$ to $1.557(1550 \mathrm{~nm})$ and 1.517 to 1.504 for $\mathrm{TiO}_{2}-\mathrm{SiO}_{2}$ and $\mathrm{ZrO}_{2}-\mathrm{SiO}_{2}$ layers, respectively. This highlights the fact that important $\Delta \mathrm{n}$ can be achieved ranging from $6.3 \times 10^{-2}$ to $5.3 \times 10^{-2}$, as observed in Table 2, meaning that such bilayers can be of interest regarding the manufacturing of sensors based on light transport. The refractive index value is determined by the polymerization degree induced by a light source exposure. For these particular layers, once a full polymerization is achieved, the refractive index remains constant, whatever the accumulated dose and the source (UV or X-rays), as indicated in a previous study [27]. 


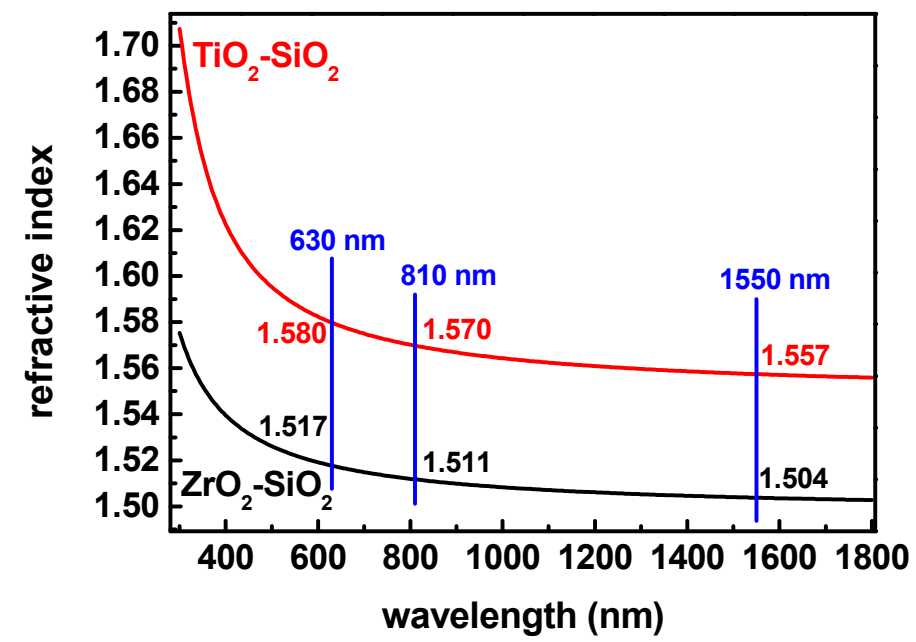

Figure 11. Refractive index of $\mathrm{TiO}_{2}-\mathrm{SiO}_{2}$ (red line) and $\mathrm{ZrO}_{2}-\mathrm{SiO}_{2}$ (black line) obtained by the ellipsometry technique. The layers were insolated by UV photons and thermally treated.

Table 2. Refractive index (n) obtained for $\mathrm{TiO}_{2}-\mathrm{SiO}_{2}$ and $\mathrm{ZrO}_{2}-\mathrm{SiO}_{2}$ films. The corresponding $\Delta \mathrm{n}$ is given for the three wavelengths of interest: 630,810 and $1550 \mathrm{~nm}$.

\begin{tabular}{cccc}
\hline Wavelength $(\mathbf{n m})$ & $\mathbf{n}\left(\mathrm{TiO}_{\mathbf{2}}-\mathbf{S i O}_{\mathbf{2}}\right)$ & $\mathbf{n}\left(\mathrm{ZrO}_{\mathbf{2}}-\mathbf{S i O}_{\mathbf{2}}\right)$ & $\boldsymbol{\Delta} \mathbf{n}$ \\
\hline 630 & 1.580 & 1.517 & $6.3 \times 10^{-2}$ \\
810 & 1.570 & 1.511 & $5.9 \times 10^{-2}$ \\
1550 & 1.557 & 1.504 & $5.3 \times 10^{-2}$ \\
\hline
\end{tabular}

It is to remind that the $\mathrm{TiO}_{2}-\mathrm{SiO}_{2}$ layer acting as the core of the photonic sensor is deposited on a soda-lime glass substrate. This particular substrate was deeply investigated in the past, especially its optical properties, such as the refractive index [28]. The values regarding the three wavelengths of interest are reported in Table 3. Interestingly, the corresponding refractive index is quite similar to the indices of the $\mathrm{ZrO}_{2}-\mathrm{SiO}_{2}$ films inducing $\Delta \mathrm{n}$ very close to the ones deduced from Table 2 . This result clearly implies that both $\mathrm{ZrO}_{2}-\mathrm{SiO}_{2}$ layers and soda-lime glass substrate have the same behavior, namely in terms of refractive index.

Table 3. Refractive index (n) obtained for $\mathrm{TiO}_{2}-\mathrm{SiO}_{2}$ films and soda-lime substrates. The corresponding $\Delta \mathrm{n}$ is given for the three wavelengths of interest: 630,810 and $1550 \mathrm{~nm}$.

\begin{tabular}{cccc}
\hline Wavelength $(\mathbf{n m})$ & $\mathbf{n}\left(\mathrm{TiO}_{\mathbf{2}}-\mathbf{S i O}_{\mathbf{2}}\right)$ & $\mathbf{n}$ (Soda Lime Glass) & $\boldsymbol{\Delta} \mathbf{n}$ \\
\hline 630 & 1.580 & 1.522 & $5.8 \times 10^{-2}$ \\
810 & 1.570 & 1.517 & $5.3 \times 10^{-2}$ \\
1550 & 1.557 & 1.507 & $5.0 \times 10^{-2}$ \\
\hline
\end{tabular}

\subsection{Simulation of the Mode Confinement: Transverse Electric (TE) Mode}

The knowledge of the refractive indices is crucial regarding the guiding properties to perform simulations to predict the behavior of sol-gel waveguides in terms of light propagation and mode confinement. In this way, we performed a series of simulations for the first specific architecture presented in this work: the $\mathrm{TiO}_{2}-\mathrm{SiO}_{2}$ core deposited on sodalime glass and surrounded by air, as illustrated in Figure 12. Simulations of the $\mathrm{TE}_{00}$ mode are obtained for the three different wavelengths of interest. For this latter, the computation of the structure is made using a 2D multilayer waveguide mode solver developed by Hammer [29], inspecting the corresponding optical field patterns. The simulations are then performed by taking into account the refractive index obtained by ellipsometry and the ones from the soda-lime substrate. Moreover, we fixed the structure width at $10 \mu \mathrm{m}$, 
while the thickness is $5 \mu \mathrm{m}$. Those values are easily obtained using the direct writing technique and the spin coating approach, respectively. From Figure 12, it is evident that the simulated modes obtained at $630 \mathrm{~nm}$ (a), $810 \mathrm{~nm}$ (b) and $1550 \mathrm{~nm}$ (c) show satisfying mode confinement mainly due to the high $\Delta \mathrm{n}$ between the core and the substrate. This SHM sensor based on light transport can operate over a large wavelength range from the visible to the IR.

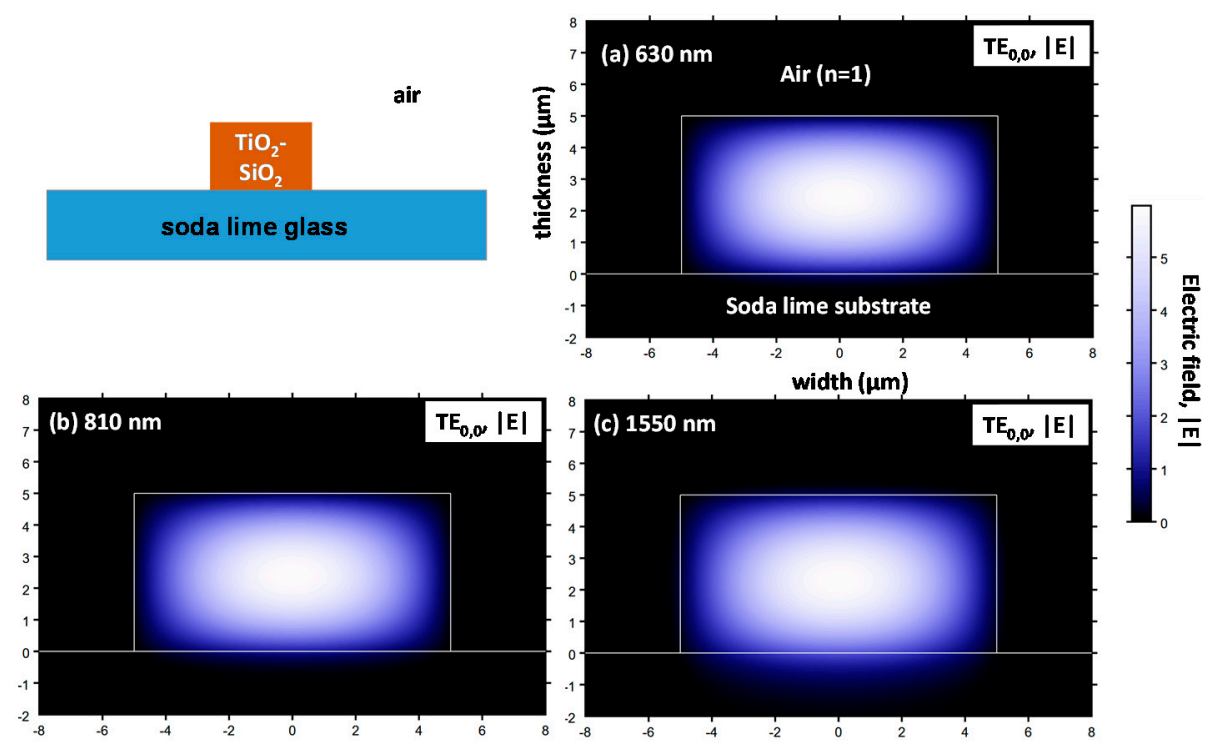

Figure 12. Simulated transverse electric $\mathrm{TE}_{00}$ mode of $\mathrm{TiO}_{2}-\mathrm{SiO}_{2}$ waveguide deposited on a sodalime glass surrounded by air and operating at (a) $630 \mathrm{~nm}$, (b) $810 \mathrm{~nm}$ and (c) $1550 \mathrm{~nm}$. The thicknesses and widths are $5 \mu \mathrm{m}$ and $10 \mu \mathrm{m}$, respectively.

The second architecture to be computed corresponds to the $\mathrm{TiO}_{2}-\mathrm{SiO}_{2}$ core deposited on soda-lime glass and surrounded by the $\mathrm{ZrO}_{2}-\mathrm{SiO}_{2}$ cladding acting like a protective layer (Figure 13). The thicknesses and widths are the same as the ones presented in Figure 12. From this Figure, it is evident that the mode is still largely confined for $630 \mathrm{~nm}$ (a) and $810 \mathrm{~nm}(\mathrm{~b})$. Even if the light is well confined for a $1550 \mathrm{~nm}$ wavelength (c), a very negligible part of the light is guided in the cladding. The soda-lime glass and the cladding having a quite similar refractive index. The core is then surrounded by a constant refractive index, whatever the direction. Obviously, the photonic sensor will be implemented on aircraft wings. Its optical properties and, more specifically, the refractive index can have a nonfavorable environment regarding light propagation. To overcome this issue, to insulate the core waveguide from the wings, a $\mathrm{ZrO}_{2}-\mathrm{SiO}_{2}$ layer can be added between them, working as a buffer layer. Thus, the final sensor will have optical responses very close to the simulation obtained in Figures 12 and 13.

In addition to the optical mode profiles given in Figures 12 and 13, the confinement factor $(\Gamma)$ was also provided through the simulation. This quantity refers to the ratio of the power in the dielectric waveguide to the total guided power and is largely described in the literature [30]. For this latter, a value close to the unit means very high light confinement. Having a strong $\Gamma$ is of great importance since the optical mode must be well insulated from any high index materials constituting the aircraft. The results for the three wavelengths are presented in Table 4 for the guide deposited on soda-lime glass and placed in the air $\left(\Gamma_{1}\right)$ or surrounded by the $\mathrm{ZrO}_{2}-\mathrm{SiO}_{2}$ cladding $\left(\Gamma_{2}\right)$ as represented in Figures 12 and 13, respectively. The $\Gamma_{1}$ values are very high, ranging from 0.999 to 0.980 for the visible and IR domains, while $\Gamma_{2}$ values of 0.998 to 0.976 are achieved. Even if these quantities are globally lower than $\Gamma_{1}$ values, $\Gamma_{2}$ remains largely acceptable, indicating the high mode confinement. Moreover, the simulated results are higher than those obtained for optical fibers, where values of 0.85 can be reported at $1550 \mathrm{~nm}$ [31]. This can be explained by 
the high $\Delta \mathrm{n}$ achieved in the $10^{-2}$ range, while values of typically $10^{-3}$ are possible for optical fibers.
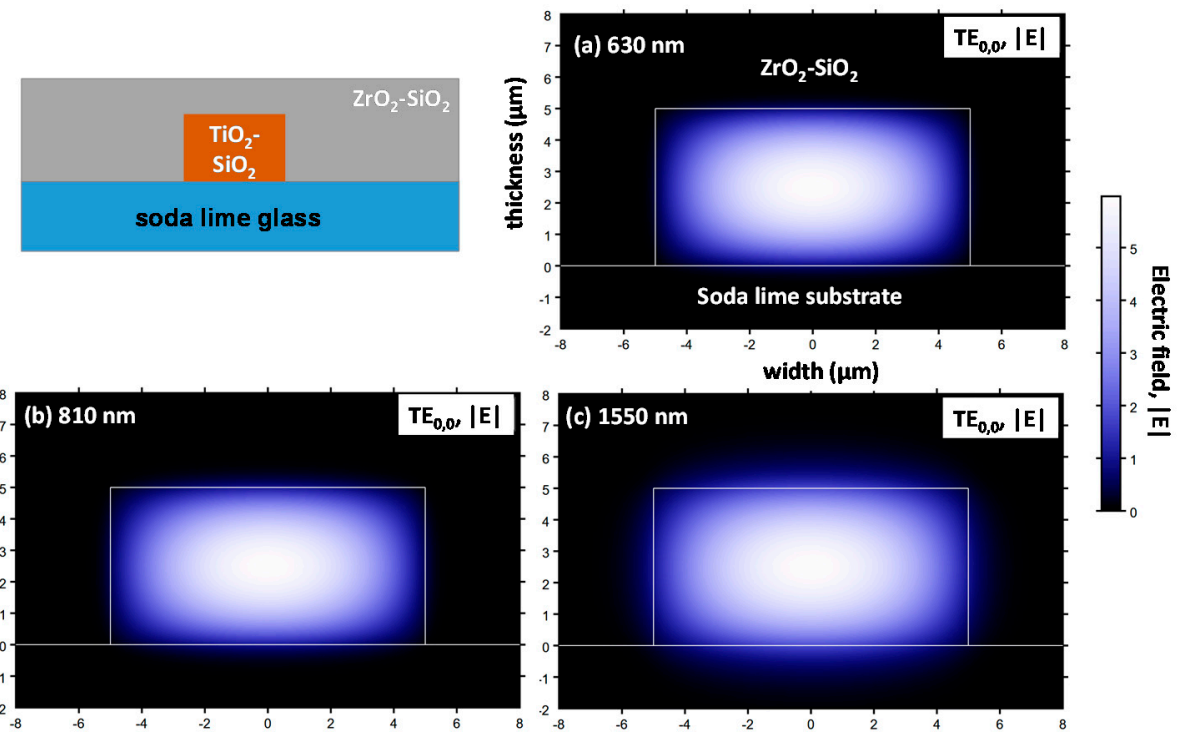

Figure 13. Simulated $\mathrm{TE}_{00}$ mode of a $\mathrm{TiO}_{2}-\mathrm{SiO}_{2}$ waveguide deposited on soda-lime glass and surrounded by the $\mathrm{ZrO}_{2}-\mathrm{SiO}_{2}$ cladding and operating at (a) $630 \mathrm{~nm}$, (b) $810 \mathrm{~nm}$ and (c) $1550 \mathrm{~nm}$. The thicknesses and widths are $5 \mu \mathrm{m}$ and $10 \mu \mathrm{m}$, respectively.

Table 4. Confinement factor $\Gamma$ for the two architectures presented: the guide, deposited on a soda-lime glass substrate, is surrounded by the air $\left(\Gamma_{1}\right)$ or by the $\mathrm{ZrO}_{2}-\mathrm{SiO}_{2}$ cladding layer $\left(\Gamma_{2}\right)$.

\begin{tabular}{ccc}
\hline Wavelength $(\mathbf{n m})$ & $\Gamma_{\mathbf{1}}$ (Surrounded by Air) & $\Gamma_{\mathbf{2}}$ (Surrounded by Cladding) \\
\hline 630 & 0.999 & 0.998 \\
810 & 0.998 & 0.996 \\
1550 & 0.980 & 0.976 \\
\hline
\end{tabular}

\subsection{Optical Properties of the Sol-Gel Device}

The refractive index being evaluated, this part aims at checking the guiding properties of the sol-gel structures (with and without $\mathrm{ZrO}_{2}-\mathrm{SiO}_{2}$ cladding) elaborated by the direct laser-writing technique. We can observe that all the waveguides studied in this section have a similar strict shape: a thickness of $5 \mu \mathrm{m}$ and a width of roughly $10 \mu \mathrm{m}$, thus corresponding to the simulated parameters reported in Section 3.5. Moreover, to perform optical testing, both ends must be cleaved for a proper light injection and collection. It is to remind that an SMF28 fiber (core of $8 \mu \mathrm{m}$ ) is used for injecting light through a buttcoupling configuration. For instance, Figure 14 focuses on the light propagation behavior inside $\mathrm{TiO}_{2}-\mathrm{SiO}_{2}$ waveguides deposited on soda-lime glass substrates and surrounded by air $(\mathrm{n}=1)$, while two wavelengths are investigated: $638 \mathrm{~nm}$ and $1550 \mathrm{~nm}$. Figure 14a illustrates a top-view image obtained by a microscope and a camera. This overview is necessary to optimize the connection between the SMF28 and the sol-gel device, thus influencing the optical mode intensity. In this Figure, we can clearly observe the SMF28 (left) injecting visible light (at $638 \mathrm{~nm}$ ) through a butt-coupling approach. The waveguide is illuminated, indicating the light transport: the best alignment possible is achieved by optimizing the waveguide illumination. Additionally, a second camera coupled with a microscope objective provides the optical mode at $638 \mathrm{~nm}$, as illustrated in Figure 14b. For this latter, it is obvious that important guiding properties are observed at $638 \mathrm{~nm}$, where the signal reveals an intense optical mode. IR light-emitting at $1550 \mathrm{~nm}$ was also used to investigate the optical properties. To this aim, Figure 14c shows the optical mode of a 
$\mathrm{TiO}_{2}-\mathrm{SiO}_{2}$ surrounded by air. As expected, the light is still largely present at the output, confirming excellent transmission properties from the visible to IR.

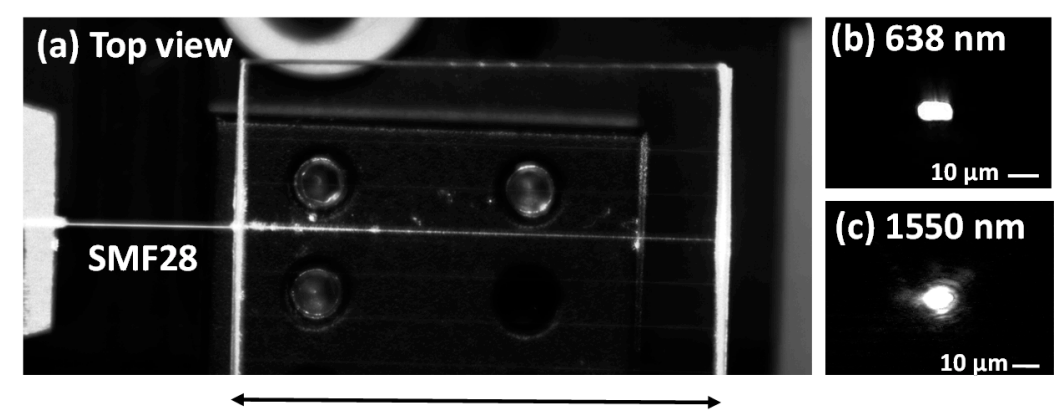

Substrate: $2.5 \mathrm{~cm}$

Figure 14. Characterization of $\mathrm{TiO}_{2}-\mathrm{SiO}_{2}$ waveguides (surrounded by air). The figure illustrates: (a) top-view of the waveguide injection at $638 \mathrm{~nm}$, (b) output optical guided mode at $638 \mathrm{~nm}$ and (c) guided mode at $1550 \mathrm{~nm}$.

The second architecture (core and cladding) was also investigated in terms of guiding properties using a $638 \mathrm{~nm}$ wavelength, as illustrated in Figure 15, and two specific cases were pointed out. The first case corresponds to the SMF28 that is not aligned with the $\mathrm{TiO}_{2}-\mathrm{SiO}_{2}$ core waveguide as schematized in Figure 15a. For this specific configuration, the cladding is illuminated, as observed in Figure 15b. However, when the SMF28 is aligned with the waveguide (Figure 15c), we can see that the light propagates inside the core insofar as the refractive index is higher compared with the cladding. The resulting guiding mode, observed in Figure 15d, remains intense, revealing important guiding properties. Through Figures 14 and 15, the study of the experimental guided modes confirms the simulated results and definitely indicates the fact that this sol-gel sensor can be based on light transport.
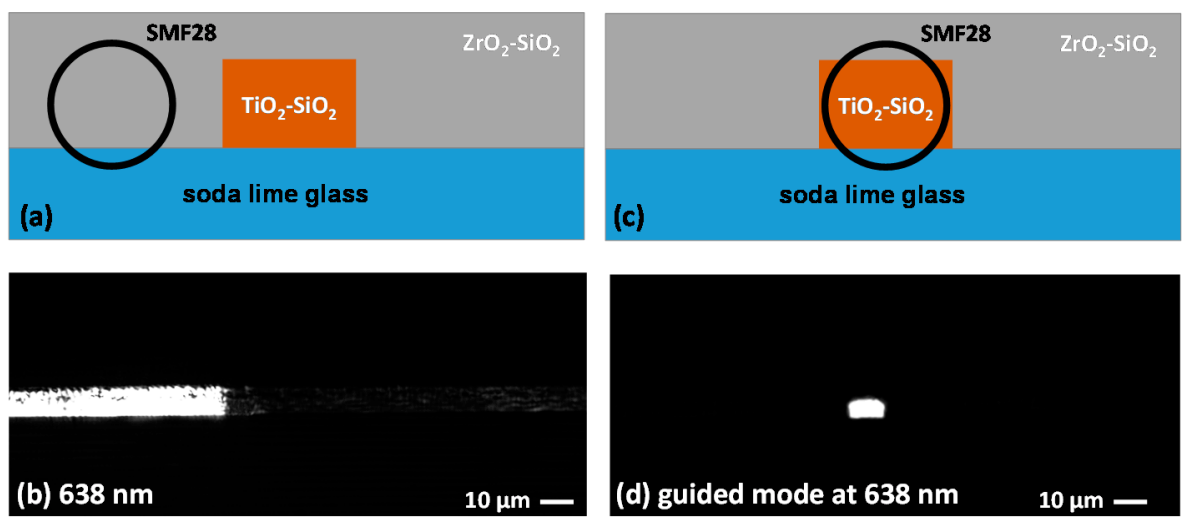

Figure 15. Injection of visible light $(638 \mathrm{~nm})$ in the architecture composed of the $\mathrm{TiO}_{2}-\mathrm{SiO}_{2}$ core deposited on soda-lime glass and surrounded by the $\mathrm{ZrO}_{2}-\mathrm{SiO}_{2}$ cladding. (a) Diagram of the SMF28 misaligned with the core, (b) corresponding output, (c) diagram of SMF28 aligned with the core and (d) corresponding guided mode. The SMF28 is schematized by black circles.

\subsection{Damage Detection and $\mathrm{TiO}_{2}-\mathrm{SiO}_{2}$ Waveguide Matrix Characterization}

This part aims to indicate the feasibility of using such a device as a damage sensor. The results presented below are related to the case where the $\mathrm{TiO}_{2}-\mathrm{SiO}_{2}$ waveguide is deposited on soda-lime glass and surrounded by the air, while the used wavelength is $638 \mathrm{~nm}$. To this aim, Figure 16a-c illustrates a waveguide before any impact through the top-view image, a microscope image where no alteration occurs and a guided mode at $638 \mathrm{~nm}$, respectively, showing the satisfying guided properties. A series of damages 
were made on the substrate until affecting one of the guides. After being impacted, the waveguide is not fully illuminated, as shown in Figure 16d, and the light extinction occurs at the specific place of the damage. To this aim, a microscope image given in Figure 16e reveals the impacted zone clearly showing the broken waveguide with an impacted area of roughly $200 \mu \mathrm{m}$. For this latter, the characterization of the optical mode was also performed. The result presented in Figure $16 \mathrm{f}$ shows the alteration of the mode and the absence of light after the damage, as suggested by Figure 16d. This first preliminary result highlights that this device based on the light transport can operate as an on/off sensor since a full, intense mode is obtained when the waveguide is not impacted, whereas the mode is totally lost after the damage.
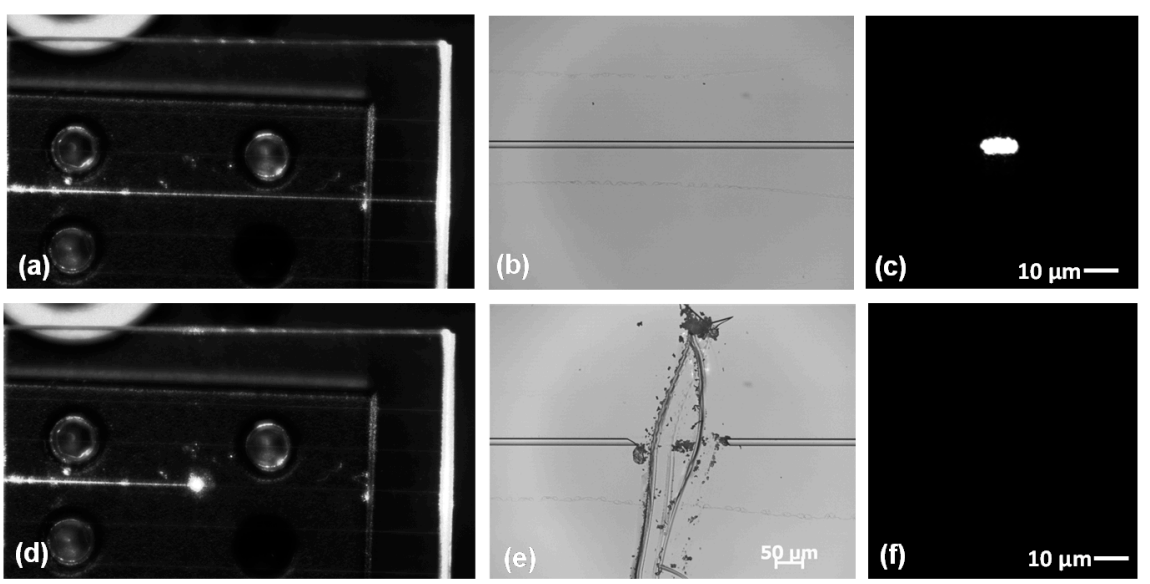

Figure 16. Damage detection with a $\mathrm{TiO}_{2}-\mathrm{SiO}_{2}$ waveguide operating at $638 \mathrm{~nm}$ showing: (a) top-view of the unaffected guide before the impact, (b) corresponding microscope image and (c) guided mode. After the impact: (d) top-view, (e) microscope image and (f) absence mode observation.

The final sensor should have a 2D matrix architecture to map the localization of damages, as illustrated in Figure 1. It is thus essential to know the behavior of light propagation through several perpendicular waveguides where too many losses between two crossed guides can drastically affect the performance of the sol-gel device. To this aim, particular attention is given in Figure 17 by investigating the light propagation at $638 \mathrm{~nm}$ after passing several perpendicular $\mathrm{TiO}_{2}-\mathrm{SiO}_{2}$ waveguides surrounded by air. We investigated two configurations, and the first one is depicted in Figure 17a. Light is injected inside a waveguide, while 6 perpendicular waveguides separated by a $3 \mathrm{~mm}$ distance are present. The top-view images the propagation of light and reveals that some losses are present after passing through perpendicular guides. Interestingly, we can observe that the corresponding optical mode is shown in the inset clearly indicate a very intense light collection and seems to be unaffected. Additionally, a second matrix was created with 12 perpendicular waveguides spaced by a $1 \mathrm{~mm}$ distance, and the result is illustrated in Figure 17b. The same behavior is achieved, and the corresponding inset reveals the satisfying optical mode where a high light collection is still present. The optical mode remains very intense despite doubling the number of perpendicular waveguides. This result highlights that low losses are induced between two crossed waveguides, a key point regarding the manufacturing of this sensor on large surfaces. 

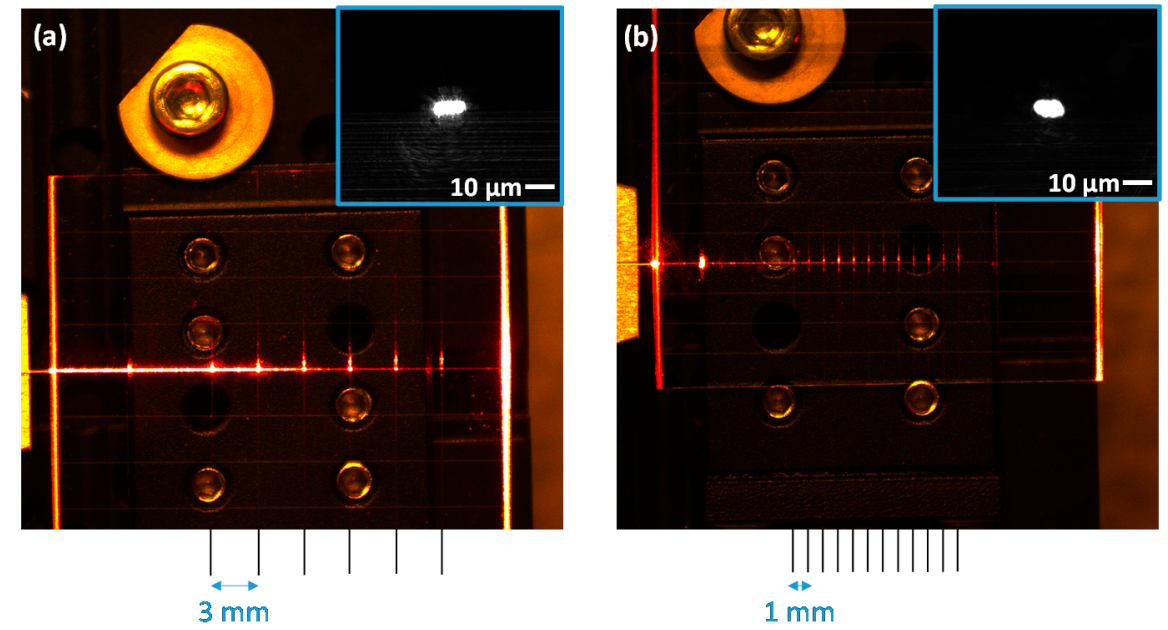

Figure 17. Top-view of $\mathrm{TiO}_{2}-\mathrm{SiO}_{2}$ waveguide grid after signal injection at $638 \mathrm{~nm}$ for (a) 6 perpendicular waveguides spaced by $3 \mathrm{~mm}$ and (b) 12 perpendicular waveguides spaced by $1 \mathrm{~mm}$. In both cases, the corresponding inset illustrates the guided mode at $638 \mathrm{~nm}$, and the waveguides are surrounded by air.

\subsection{Thermal Behavior of $\mathrm{TiO}_{2}-\mathrm{SiO}_{2}$ Waveguides}

The $\mathrm{TiO}_{2}-\mathrm{SiO}_{2}$ waveguides will be implemented on aircraft wings in the future. It is thus essential to know the behavior of this kind of material for different temperatures that are representative of the ones obtained between the takeoff and landing, where thermal dilation or shrinkage can occur, impacting the mechanical resistance directly. To this aim, we checked the behavior of $10 \mathrm{~cm} \times 10 \mathrm{~cm} \mathrm{TiO}{ }_{2}-\mathrm{SiO}_{2}$ grid waveguides submitted to thermal cycling ranging from two extremal values: $-40{ }^{\circ} \mathrm{C}$ to $80{ }^{\circ} \mathrm{C}$. It is to note that each waveguide is separated by a $5 \mathrm{~mm}$ distance in both directions. After creating the waveguides followed by a final thermal treatment at $90{ }^{\circ} \mathrm{C}$ to stabilize the structure, the device was located in an oven, and Figure 18 illustrates the experimental conditions. The same sample was submitted to a cycle of 13 consecutive temperature levels with a step of $20^{\circ} \mathrm{C}$, each lasting $1 \mathrm{~h}$. More specifically, the thermal cycling is divided into three steps: a first temperature increase from $20^{\circ} \mathrm{C}$ to $80^{\circ} \mathrm{C}$, followed by a decrease down to $-40^{\circ} \mathrm{C}$. Finally, the sample was submitted to increasing temperatures to reach the ultimate $20^{\circ} \mathrm{C}$ temperature. After each temperature level, profilometer measurements and microscope images are recorded to check if sol-gel waveguides are impacted and affected by these extreme temperature changes. For this experiment, it is important to note that the cladding is absent so that profilometer measurements can be easily performed, thus providing the shape (width and thickness) of the different waveguides and a potential influence.

The results regarding thermal cycling are presented in Figure 19. To this aim, this latter reveals microscope images of the crossed area for several points of interest: the pristine structure before the thermal cycling (a), after being treated at $80^{\circ} \mathrm{C}(\mathrm{b})$ and $-40{ }^{\circ} \mathrm{C}(\mathrm{c})$. After all the consecutive thermal treatments, the architecture is also imaged through the pictures given in (d), and it seems that the crossed area and consequently the waveguides are not affected by all the temperature levels. In addition, complementary profilometer measurements (SF $=10 \mathrm{mg}$ ) were obtained and illustrated in Figure 19e. Interestingly, it is to note that both shapes and widths remain strictly similar for the four cases presented: before the thermal cycling (black line), after $80^{\circ} \mathrm{C}$ (red line), $-40{ }^{\circ} \mathrm{C}$ (blue line) and after all the thermal treatments (magenta line). Finally, after being exposed to the entire thermal treatment cycle, the hardness of the structure is evaluated, as it is shown in Figure 19f. Indeed, a first profilometer measurement was performed using an SF of $10 \mathrm{mg}$ (black line), while a second one is realized at the same exact position without altering the waveguides. The last measurement (blue line) was achieved at the same place using the highest SF $(15 \mathrm{mg})$ available for this experimental setup and clearly showed that the guide remains unaffected. It is obvious that contacting several times the structures submitted to thermal 
cycling will leave the sol-gel structure unaffected. This result clearly indicates that a high mechanical resistance is still present despite the thermal cycling: no dilation or shrinkage occurs, highlighting the fact that sol-gel devices can be used in the aerospace domain due to high thermal stability.

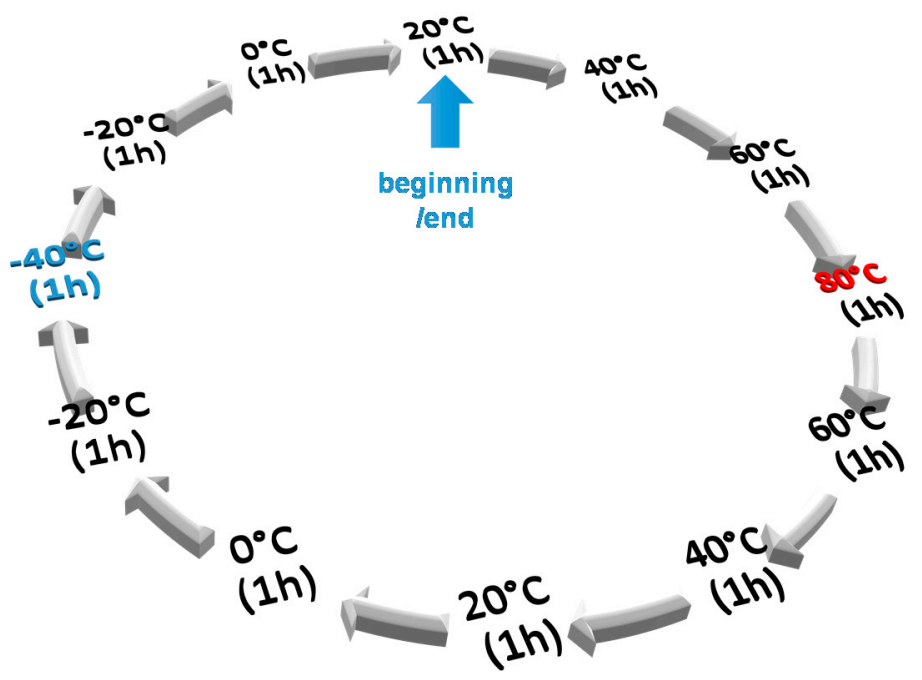

Figure 18. Thermal cycling performed on a $10 \mathrm{~cm} \times 10 \mathrm{~cm} \mathrm{TiO}{ }_{2}-\mathrm{SiO}_{2}$ grid architecture divided into three steps: a first increase from $20{ }^{\circ} \mathrm{C}$ to $80^{\circ} \mathrm{C}$ followed by a decrease down to $-40{ }^{\circ} \mathrm{C}$, while the last increase is performed to reach $20^{\circ} \mathrm{C}$. Each temperature level lasts $1 \mathrm{~h}$.
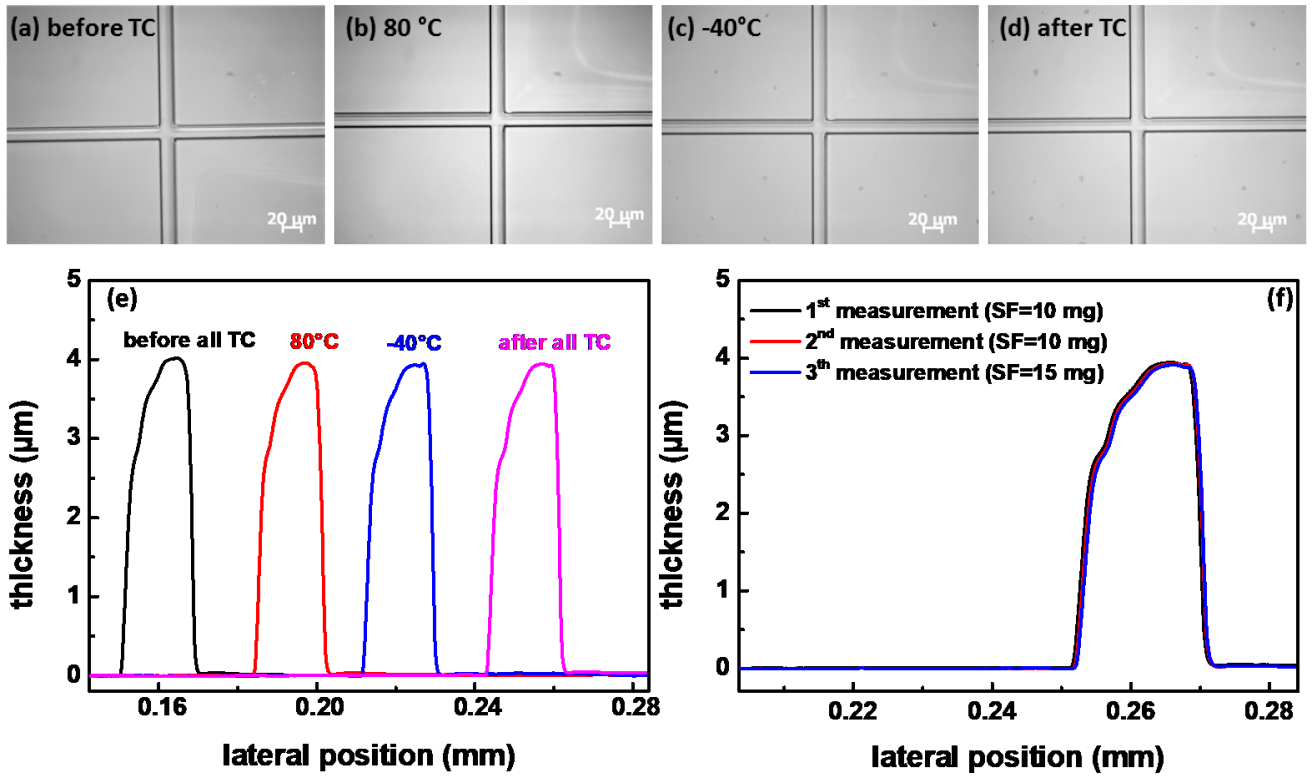

Figure 19. Thermal cycling (TC) effect on $\mathrm{TiO}_{2}-\mathrm{SiO}_{2}$ grid architecture. Microscope images of the grid area are given (a) before the thermal cycling, (b) after being thermally treated at $80^{\circ} \mathrm{C},(\mathbf{c})-40{ }^{\circ} \mathrm{C}$ and (d) after all the consecutive thermal treatments. (e) Corresponding profilometer measurements ( $\mathrm{SF}=10 \mathrm{mg}$ ) and (f) profilometer measurements of the structure submitted to the full thermal cycling with SF of $10 \mathrm{mg}$ (black and red lines) and $15 \mathrm{mg}$ (blue line).

\section{Conclusions}

In the framework of the ADD-ON project (H2020), we showed the feasibility of using the sol-gel approach for functionalizing large surfaces for SHM in the aerospace domain. More specifically, a sol-gel sensor based on waveguides inscribed by UV photolithography on a $2 \mathrm{D}$ matrix was reported using $\mathrm{TiO}_{2}-\mathrm{SiO}_{2}$ and $\mathrm{ZrO}_{2}-\mathrm{SiO}_{2}$ sol-gels acting as the waveg- 
uide core and cladding, respectively. The results show that the structures can be easily manufactured on large surfaces using the direct laser-writing approach where varying the laser energy and the scanning speed allows tuning the shape of the photo-induced architectures. Additionally, the refractive indices of the sol-gel layers obtained by ellipsometry are adequate with important $\Delta \mathrm{n}$ from the visible to IR spectral range. Both the simulation and experimental approaches show the high guiding properties of the 1D or 2D structures through satisfying mode confinement in both visible and infrared domains. Preliminary tests were obtained showing that the photonic structure can act as an on/off sensor insofar as damages can be detected related to the optical mode extinction. Light injection in a waveguide grid clearly indicates that its performances remain unaffected after passing through multiple waveguides leading to the possibility of using such sensors on large surfaces. Finally, the resistance to thermal cycling ranging from $-40^{\circ} \mathrm{C}$ to $80^{\circ} \mathrm{C}$ was performed clearly, indicating that the structure is unaltered and no dilation or shrinkage occurs. This proof of concept sensor is then a promising tool regarding the SHM (damage and delamination detection) of aircraft. Obviously, further investigations will be performed to achieve the implementation onto aircraft wings and the permanent coupling of all the waveguides with light sources. To convert such a sensor into a fully efficient tool for SHM, complementary approaches are under development to multiply the number of guides probed with a unique source.

Author Contributions: Conceptualization, M.R., D.J., E.M., M.-A.d.S. and S.G.; methodology, M.R., T.B., F.V., D.J., E.M., A.M. and S.G.; software, D.J.; validation, M.R., D.J., F.V., Y.J., R.E., T.V.L., M.-A.d.S. and S.G.; formal analysis, M.R. and D.J.; investigation, M.R., T.B., D.J., E.M., A.M., R.E., T.V.L., M.-A.d.S. and S.G.; resources, F.V., D.J., A.B., Y.J., F.R. and Y.O.; data curation, D.J.; writing-original draft preparation, M.R.; writing—review and editing, M.R., D.J., F.R., F.V., E.M., A.M., Y.O., Y.J., T.V.L., M.-A.d.S. and S.G.; visualization, M.R.; supervision, Y.J., M.-A.d.S. and S.G.; project administration, M.-A.d.S. and S.G.; funding acquisition, M.-A.d.S. and S.G. All authors have read and agreed to the published version of the manuscript.

Funding: This project has received funding from the Clean Sky 2 Joint Undertaking under the European Union's Horizon 2020 research and innovation program under grant agreement $\mathrm{N}^{\circ} 785341$.

Institutional Review Board Statement: Not applicable.

Informed Consent Statement: Not applicable.

Acknowledgments: This work was partly supported by the French RENATECH+ network led by the CNRS on the NanoSaintEtienne platform.

Conflicts of Interest: The authors declare no conflict of interest.

\section{References}

1. Qing, X.; Li, W.; Wang, Y.; Sun, H. Piezoelectric Transducer-Based Structural Health Monitoring for Aircraft Applications. Sensors 2019, 19, 545. [CrossRef] [PubMed]

2. Staszewski, W.J.; Mahzan, S.; Traynor, R. Health monitoring of aerospace composite structures-Active and passive approach. Compos. Sci. Technol. 2008, 69, 1678-1685. [CrossRef]

3. Solimine, J.; Niezrecki, C.; Inalpolat, M. An experimental investigation into passive acoustic damage detection for structural health monitoring of wind turbine blades. Struct. Health Monit. 2020, 19, 1711-1725. [CrossRef]

4. Di Sante, R. Fibre Optic Sensors for Structural Health Monitoring of Aircraft Composite Structures: Recent Advances and Applications. Sensors 2015, 15, 18666-18713. [CrossRef]

5. Lee, B.H.; Kim, Y.H.; Park, K.S.; Eom, J.B.; Kim, M.J.; Rho, B.S.; Choi, H.Y. Interferometric Fiber Optic Sensors. Sensors 2012, 12, 2467-2486. [CrossRef]

6. Takeda, N.; Okabe, Y.; Mizutani, T. Damage detection in composites using optical fibre sensors. Proc. Inst. Mech. Eng. G 2007, 221, 497-508. [CrossRef]

7. Güemes, A.; Fernandez-Lopez, A.; Soller, B. Optical fiber distributed sensing- Physical principles and applications. Struct. Health Monit. 2010, 9, 233-245. [CrossRef]

8. Agustín-Sáenz, C.; Santa Coloma, P.; Fernández-Carretero, F.J.; Brusciotti, F.; Brizuela, M. Design of Corrosion Protective and Antistatic Hybrid Sol-Gel Coatings on 6XXX AlMgSi Alloys for Aerospace Application. Coatings 2020, 10, 441. [CrossRef]

9. Catauro, M.; Mozzati, M.C.; Bollino, F. Sol-gel hybrid materials for aerospace applications: Chemical characterization and comparative investigation of the magnetic properties. Acta Astronaut. 2015, 117, 153. [CrossRef] 
10. Ouahabi, A.; Thomas, M.; Kobayashi, M.; Jen, C.K. Structural health monitoring of aerospace structures with sol-gel spray sensors. Key Eng. Mater. 2007, 347, 505-510. [CrossRef]

11. Hench, L.L.; West, J.K. The sol-gel process. Chem. Rev. 1990, 90, 33-72. [CrossRef]

12. Kaczmarek, H.; Galka, P.P. Effect of irgacure 651 initiator on poly(methyl methacryltate) photostability studied by UV-Vis spectroscopy. Open Process Chem. J. 2008, 1, 8-11. [CrossRef]

13. Segurola, J.; Allen, N.S.; Edge, M.; Roberts, I. Photochemistry and photoinduced chemical crosslinking activity of acrylated prepolymers by several commercial type I far UV photoinitiators. Polym. Degrad. Stab. 1999, 65, 153-160. [CrossRef]

14. Jerónimo, P.C.A.; Araújo, A.N.; Montenegro, M.C.B.S.M. Optical sensors and biosensors based on sol-gel films. Talanta 2007, 72, 13-27. [CrossRef] [PubMed]

15. Gelover, S.; Mondragón, P.; Jiménez, A. Titanium dioxide sol-gel deposited over glass and its application as a photocatalyst for water decontamination. J. Photochem. Photobiol. A 2003, 165, 241-246. [CrossRef]

16. Oubaha, M.; Kribich, R.K.; Copperwhite, R.; Etienne, P.; O’Dwyer, K.; MacCraith, B.D.; Moreau, Y. New inorganic sol-gel material with high transparency at $1.55 \mu \mathrm{m}$. Opt. Commun. 2005, 253, 346-351. [CrossRef]

17. Versace, D.; Oubaha, M.; Copperwhite, R.; Croutxé-Barghorn, C.; MacCraith, B. Waveguide fabrication in UV-photocurable sol-gel materials: Influence of the photoinitiating system. Thin Solid Film 2008, 516, 6448-6457. [CrossRef]

18. Custom Photolithography System: Dilase 750. Available online: https://www.kloe-france.com/en/laser-lithography/ photolithography-systems/direct-laser-writing/dilase-750 (accessed on 9 March 2021).

19. Durgapal, P.; Ehrstein, J.R.; Nguyen, N.V. Thin film ellipsometry metrology. AIP Conf. Proc. 1998, 449, $121-131$.

20. Coudray, P.; Etienne, P.; Moreau, Y.; Porque, J.; Najafi, S. Sol-gel channel waveguide on silicon: Fast direct imprinting and low cost fabrication. Opt. Commun. 1997, 143, 199-202. [CrossRef]

21. Coudray, P.; Etienne, P.; Moreau, Y. Integrated optics based on organo-mineral materials. Mat. Sci. Semincon. Process. 2000, 3 , 331-337. [CrossRef]

22. Pani, S.K.; Quiling, Y.; Wong, C.C.; Low, D.K.Y.; Zhang, X.; Lyer, M.K. Fabrication of buried hybrid sol-gel optical waveguides by femtosecond laser direct writing. Thin Solid Films 2006, 504, 336-340. [CrossRef]

23. Li, A.; Wang, Z.; Liu, J.; Zeng, X. Low cost fabrication of $\mathrm{SiO}_{2}$ optical waveguides by laser direct writing on Ti-doped sol-gel films. Opt. Lasers Eng. 2011, 49, 351-355. [CrossRef]

24. Franc, J.; Blanc, D.; Zerroukhi, A.; Chalamet, Y.; Last, A.; Destouches, N. Organo-silica-titania nanocomposite elaborated by sol-gel processing with tunable optical properties. Mater. Sci. Eng. B 2006, 129, 180-185. [CrossRef]

25. Aspnes, D.E.; Studna, A.A. Dielectric functions and optical parameters of Si, Ge, GaP, GaAs, GaSb, InP, InAs, and InSb from 1.5 to 6.0 eV. Phys. Rev. B 1982, 27, 985-1009. [CrossRef]

26. Chandler-Horowitz, D.; Amirtharaj, P.M. High-accuracy, midinfrared $\left(450 \mathrm{~cm}^{-1} \leq \omega \leq 4000 \mathrm{~cm}^{-1}\right)$ refractive index values of silicon. J. Appl. Phys. 2005, 97, 123526-123534. [CrossRef]

27. Royon, M.; Vocanson, F.; Jamon, D.; Marin, E.; Morana, A.; Boukenter, A.; Girard, S.; Ouerdane, Y.; Royer, F.; Jourlin, Y. Comparison between the UV and X-ray Photosensitivities of Hybrid $\mathrm{TiO}_{2}-\mathrm{SiO}_{2}$ Thin Layers. Materials 2020, 13, 3730. [CrossRef] [PubMed]

28. Rubin, M. Optical properties of soda lime silica glass. Sol. Energy Mater. 1985, 12, 275-288. [CrossRef]

29. Hammer, M. 2-D Multilayer Waveguide Mode Solver, Variational Effective Index Approximation. Available online: https: / / www.siio.eu/eims.html (accessed on 9 January 2021).

30. Sakai, J.I.; Sasaki, J.; Kawai, K. Optical power confinement factor in a Bragg fiber: 2. Numerical results. J. Opt. Soc. Am. B 2007, 24, 20-27. [CrossRef]

31. Li Vecchi, G.; Di Francesca, D.; Sabatier, C.; Girard, S.; Alessi, A.; Guttilla, A.; Robin, T.; Kadi, Y.; Brugger, M. Infrared radiation induced attenuation of radiation sensitive optical fibers: Influence of temperature and modal propagation. Opt. Fiber Technol. 2020, 55, 102166-102172. [CrossRef] 